\title{
Single Pile FEM Modeling: Ultimate Capacity Determination of Bored Piles Embedded in Silty-Sands Using Modified Drucker-Prager Cap Model
}

\author{
Nathaniel E. Rivera*, Gilford B. Estores \\ School of Civil, Environmental and Geological Engineering, Mapúa University, Manila, 1002, Philippines
}

Received October 11, 2021; Revised December 15, 2021; Accepted December 26, 2021

\section{Cite This Paper in the following Citation Styles}

(a): [1] Nathaniel E. Rivera, Gilford B. Estores, "Single Pile FEM Modeling: Ultimate Capacity Determination of Bored Piles Embedded in Silty-Sands using Modified Drucker-Prager Cap Model," Civil Engineering and Architecture, Vol. 10, No. 1, pp. 175 - 193, 2022. DOI: 10.13189/cea.2022.100116.

(b): Nathaniel E. Rivera, Gilford B. Estores (2022). Single Pile FEM Modeling: Ultimate Capacity Determination of Bored Piles Embedded in Silty-Sands using Modified Drucker-Prager Cap Model. Civil Engineering and Architecture, 10(1), 175 - 193. DOI: 10.13189/cea.2022.100116.

Copyright $\bigcirc 2022$ by authors, all rights reserved. Authors agree that this article remains permanently open access under the terms of the Creative Commons Attribution License 4.0 International License

\begin{abstract}
Ultimate pile capacity determination is crucial before the structure construction. This essential pile resistance can be accurately predicted and studied using the finite element method. FEM is a numerical method that is anticipated to be indispensable in advances in pile analyses, aiming at pile effectiveness and material efficiency. Pile modeling is attainable using FEM for the stability investigation concerning the geotechnical findings. In addition, several constitutive mathematical models have been available for FEM applications to reasonably simulate soil behavior under pressure. This study conducts numerical modeling of eight bored piles of different diameters and lengths embedded in silty-sand soils. Using the FEM software ABAQUS, pile load-settlement curves are obtained to determine ultimate pile capacity, skin friction resistance, and pile base resistance. The modified Drucker Prager Cap model is used as a constitutive soil model for silty sand soils. In applying the MDPC model, the cap hardening behavior (hardening parameter) is obtained by having the site soils compression and swelling indices determined using the proposed regression equations in the literature. Piles were modeled successfully, and the results positively correlate with the results of the dynamic analysis test conducted in Davao del Norte, Philippines.
\end{abstract}

Keywords Bored Piles, Finite Element Method, Modified Drucker-Prager Cap Model, Ultimate Pile Capacity, Pile Dynamic Analysis, Civil Engineering, Pile
Foundations

\section{Introduction}

The high demand for constructing essential structures in soft-soil conditions has resulted in efficient pile foundation construction. This pursuit causes the rise of analytical methods to predict ultimate pile capacity [1]. Ultimate pile capacity is the maximum compressive load that the pile can carry without exceeding its material strength or significant settlement. In a typical pile-load-settlement curve, the ultimate load of the pile occurs at settlement equals ten percent of its width or diameter. Another way of determining the ultimate load from the load settlement curve is by drawing two tangent lines and a vertical line intersecting the tangent lines' intersection. The magnitude of the load intersecting the vertical line is the ultimate capacity [2].

The most reliable procedure in determining pile integrity is by in-situ pile testing, either by Static Load Test or Pile Dynamic Analysis Test. The two tests can have different results for ultimate capacity [3]. However, these two methods can have more similarities when the PDA test results have been through Case Pile Wave Analysis Program (CAPWAP) software. This program analyzes PDA data to provide more accurate results for ultimate pile capacity [4]. Ultimate capacity can also be determined 
using analytical methods. However, most of these methods do not consider the complex behavior of soils, and they can produce results that tend to over-predict or under-predict ultimate pile capacity [5].

A tool that is widely used in studying pile foundations is the finite element method. FEM is a numerical method that offers a solution to engineering problems that involve complicated geometry [6] and material behaviors [7]. FEM has been used to study the pile-settlement behavior [8] and determine the ultimate pile capacity [9]. A crucial aspect of FEM pile modeling is applying a constitutive model for soils, i.e., predicting failure and simulating behavior [10].

Several models are available to be used in FEM software, e.g., Mohr-Coulomb, Cam clay, Drucker-Prager, and Hardening Soil. The Mohr-Coulomb, Hardening Soil, and Drucker-Prager Yield Criterion are recently the most used constitutive models in single pile foundation modeling. Mohr-Coulomb criterion shows good performance in representing the skin friction resistance of the pile in sandy soil [11]. The hardening soil model combined with the mohr-coulomb has better performance at relatively higher axial loads ( $\mathrm{P} \geq 15,000 \mathrm{KN}$ ) [12]. The Drucker-Prager yield criterion has shown good performance in simulating the behavior of sandy soils, and predicting the pile base resistance [13] settlement response [14], and predicting footing's bearing capacity [15].

The mentioned constitutive models are formulated primarily by using undisturbed soil samples. The gathered soil information must have been minimally disturbed before the FEM analysis in pile modeling. In this manner, more comparable soil conditions against the actual obtained, since strong predictors for ultimate capacity include soil properties, pile installation method, and pile characteristics [16-18].

Typically, geotechnical investigations are conducted before testing. The current state of soil can be disturbed due to pile installation, such as heavy pile driving, which alters the current state of soil due to vibration and densification. A type of pile where methods of installation produce minor soil disturbance is a bored pile. Bored piles are cast-in-place piles where installation modes are by drilling holes and pouring fresh concrete, producing less soil vibration $[2,19]$ and soil densification.

In this study, eight concrete bored piles with different lengths and diameters are modeled through the FEM software ABAQUS/CAE 2020. The piles are embedded in the cohesionless silty-sand soils in Barangay Osmeña and Kasilak, Davao del Norte, Philippines. The primary data for the modeling is the geotechnical investigation findings and pile information. The results of PDA (CAPWAP) were used to compare the results. An elastic-plastic constitutive model used is the modified Drucker-Prager Cap model, which comprises Drucker-Prager yield and Cap yield.

\subsection{Modified Drucker-Prager Cap Model}

The MDP cap model is a plasticity model used to simulate particulate and geological materials. This cap model constitutes yield criterion, hardening rule, and flow rule. A yield criterion is a set of equations that define the material's stress limit during elastic (reversible) deformation [20]. Fig. 1 shows the MDP yield criterion, which is composed of three surfaces, namely the Drucker-Prager yield $F s$, cap surface $F c$ and transition surface $F t$ which are expressed as

$$
\begin{gathered}
F_{S}=t-p \tan \beta-d=0 \\
F_{c}=\sqrt{\left(p-p_{a}\right)^{2}+\left(\frac{R t}{1+\alpha-\alpha / \cos \beta}\right)^{2}}-\mathrm{R}\left(\mathrm{d}+p_{a} \tan \beta\right)=0 \\
F_{t}=\sqrt{\left(p-p_{a}\right)^{2}+\left[t-\left(1-\frac{\alpha}{\cos \beta}\right)\left(d+p_{a} \tan \beta\right)\right]^{2}}- \\
\alpha\left(\mathrm{d}+p_{a} \tan \beta\right)=0
\end{gathered}
$$

where $t$ is the deviator stress, $p$ is the average effective stress, $d$ is the cohesion, $\mathrm{R}(0.0001 \leq \mathrm{R} \leq 1000)$ is the cap eccentricity parameter, and $\alpha(0.01-0.04)$ is the transition surface radius parameter. $p_{a}$ is the evolution parameter which is expressed as

$$
p_{a}=\frac{p_{b}-R d}{1+R \tan \beta}
$$

where $p_{b}$ is the hydrostatic compression yield stress 


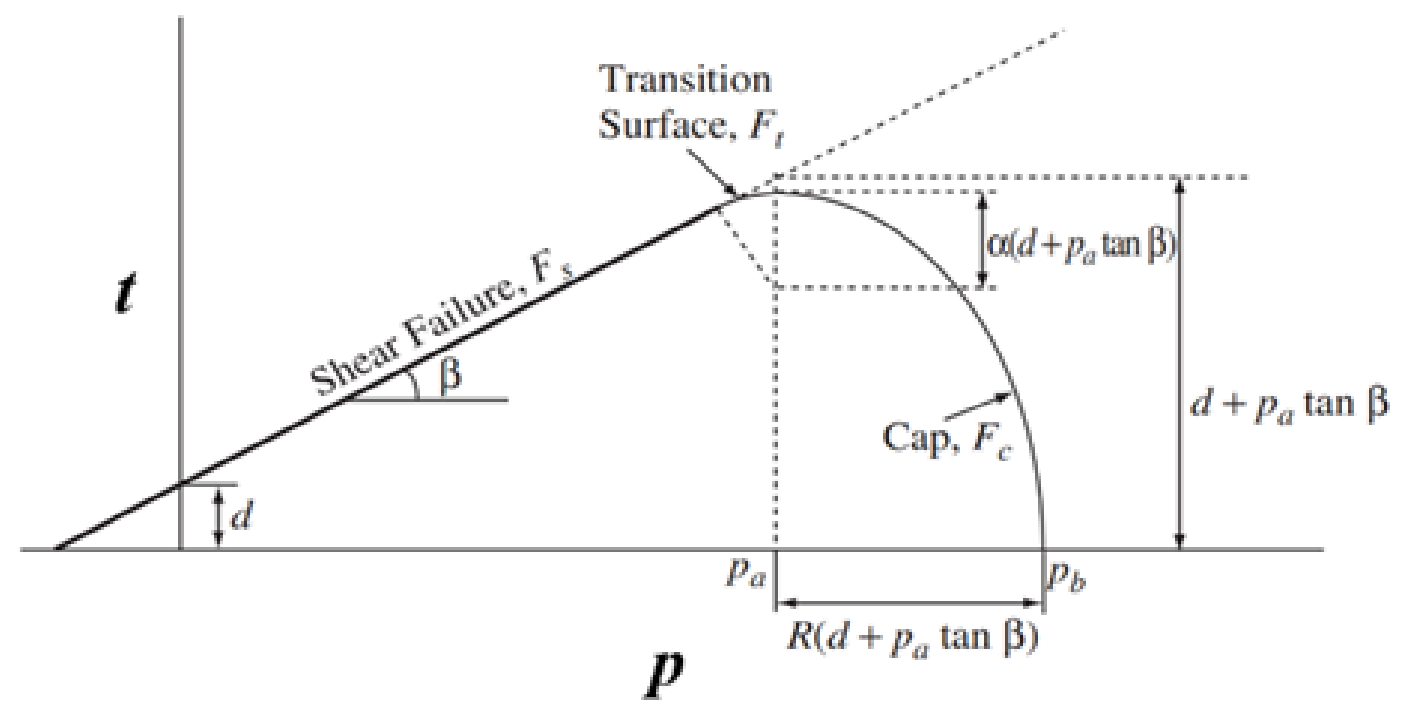

Figure 1. Modified Drucker Prager/Cap Model yield surface extracted from ABAQUS (2017)

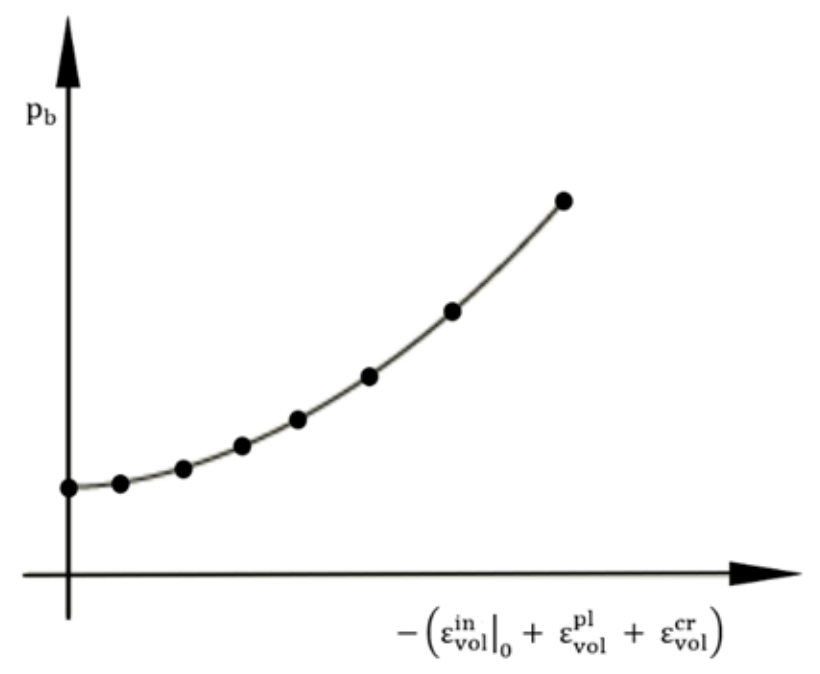

Figure 2. Typical Cap Hardening Curve extracted from ABAQUS (2017)

The Drucker-Prager yield surface or shear failure limits the level of shear stress that the material can support before the plastic yielding. In contrast, the cap yield surface provides an inelastic hardening process. The transition surface provides a smooth transition between DP yield and the cap surface. In Fig. 1, the intersection of the cap surface and the $p-q$ plane is the current state of stress of the material before it is subjected to compressive stress [21]. The cap surface represents plastic compaction and controls volume dilatancy when shear yielding occurs.

Fig. 2 shows the typical cap hardening behavior-the basis for the hardening rule, which predicts stress-strain response during plastic deformation. The soils hardening behavior is obtained by relating the hydrostatic yield stress $p_{b}$ and volumetric plastic strain $\varepsilon_{v}^{p}$.

The flow rule controls the direction of the plastic strain increment caused by the strain increment. The plastic flow includes an associated flow with the cap surface and a non-associated flow with the Drucker-Prager yield and transition surface. The shape of the former flow potential is the same as the cap, while the latter is different from the Drucker-Prager yield and transition surface. The associated $G c$ and non-associated Gs flow potential are expressed as

$$
\begin{gathered}
G_{c}=\sqrt{\left(p-p_{a}\right)^{2}+\left(\frac{R t}{1+\alpha-\alpha / \cos \beta}\right)^{2}} \\
G_{S}=\sqrt{\left[\left(p-p_{a}\right) \tan \beta\right]^{2}+\left(\frac{R t}{1+\alpha-\alpha / \cos \beta}\right)^{2}}
\end{gathered}
$$

\subsection{MDP Cap Model in FEM Pile Modeling}

The MDP cap model is practical [22] and appropriate for simulating cohesionless soils. A data of cap hardening curve is required to use this constitutive model. This curve can be obtained by conducting a hydrostatic compression test or gathering data from the literature [23]. An alternative approach is using the plastic volumetric strain equation [10], which is mathematically derived from a semi-log plot of a consolidation test, and expressed as [24]

$$
\varepsilon_{v}^{p}=\frac{\mathrm{C}_{\mathrm{c}}-\mathrm{C}_{\mathrm{s}}}{2.3\left(1+\mathrm{e}_{0}\right)} \ln \frac{P^{\prime}}{P_{0}^{\prime}}
$$

where $\mathrm{Cc}$ is the soil's compression index, Cs is soil's swelling index and $P_{0}^{\prime}$ is the initial average stress.

A sensible alternative approach would be providing a cap hardening curve by obtaining appropriate proposed regression equations from the literature. This method was never done before in FEM pile modeling. These proposed equations are handy to apply in any problems since the parameters required are typical soil parameters [25-30] and can be found in typical geotechnical reports.

The results of the static loading test (SLT) or pile dynamic analysis test (PDA) would be reasonable as credible validation for the FEM pile models. Additionally, these methods are credibly used and locally and globally acknowledged in-situ testing methods $[31,32]$. Moreover, 
Ultimate Capacity Determination of Bored Piles Embedded in Silty-Sands Using Modified Drucker-Prager Cap Model

the widely used analytical methods of Meyerhof (1976), Coyle \& Castello (1981), and the Beta method can also be used. These methods are used for calculating the ultimate resistance of piles embedded in sands or cohesionless soil, thus sensible for comparing the results with the FEM models $[18,33]$.

In conducting FEM pile modeling, the specific objectives of this study are the following:

1. To implement Modified Drucker-Prager Cap Model as a soil model, mathematically representing the soil behavior of the silty sand soil.

2. To determine the probable in-situ compression $(\mathrm{Cc})$ and swelling (Cs) indexes of the soils by using the appropriate proposed equations in the literature to obtain the evolution of the theoretical plastic volumetric strain (or the cap hardening behavior) of the sites' soil as a conjunction to MDPC model.

3. To evaluate FEM pile modeling results by comparing the ultimate capacity results against the results of the Pile Dynamic Analysis Test (CAPWAP).

4. To assess the performance of the FEM models by performing regression analysis and test for the null hypothesis, namely the one-way ANOVA test, T-test, and P-value.

5. To assess the performance of the FEM models by comparing the results to the analytical methods' results.

\section{Materials and Methods}

ABAQUS/CAE 2020 student version is used in the FEM modeling. This version limits the maximum number of nodes to one thousand. Implementation of efficient model dimensions is observed to avoid the node number limit and have a finer mesh. An axisymmetric problem is adopted for the modeling to leverage symmetry. A four-node bilinear-axisymmetric quadrilateral-reduced integration element (CAX4R) is adopted in modeling the pile. At the same time, a four-node-axisymmetric quadrilateral-bilinear pore pressure element (CAX4P) is adopted in modeling the soil. Fig. 3 shows the basis of the models' dimensions. A "symmetry" boundary condition is applied on the left vertical edges. The bottom edge of the soil geometry is fixed in the horizontal and vertical direction, and the vertical edge in the right end is fixed only in the horizontal direction.

Table 1 shows the pile characteristics and properties. Linear elastic behavior is adopted for the pile. Table 2 shows the soil properties of the models. These values are based on the bore-log investigation through ASTM procedures. The soil classification in this study is a cohesionless, dense silty-sands as per the unified soil classification system (ASTM-D2487), with very low to zero plastic and liquid limits. Values for the permeability $\mathrm{k}$ and Poisson's ratio is taken as $1 \times 10^{-6} \mathrm{~m} / \mathrm{s}$ and 0.20 for the relatively high permeable and dense silty sand soils
The modified Drucker-Prager Cap model is implemented as the constitutive model for the soil. Moreover, a linear isotropic type is adopted for elastic behavior.

Table 1. Bored Pile Properties and Characteristics

\begin{tabular}{|c|c|c|c|c|c|}
\hline Model & $\mathbf{L}(\mathbf{m})$ & $\mathbf{D}(\mathbf{m})$ & $\begin{array}{c}\boldsymbol{\rho}_{\boldsymbol{m}}(\boldsymbol{k g} / \\
\left.\boldsymbol{m}^{\mathbf{3}}\right)\end{array}$ & $\boldsymbol{E}_{\boldsymbol{s}}(\mathbf{P a})$ & $\mathbf{v}$ \\
\hline O-AB-A & 30 & 1.4 & 2500 & $3.42 \mathrm{E}+10$ & 0.15 \\
\hline O-AB-B & 30 & 1.4 & 2500 & $3.42 \mathrm{E}+10$ & 0.15 \\
\hline O-P-1 & 40 & 1.8 & 2500 & $4.41 \mathrm{E}+10$ & 0.15 \\
\hline O-P-2 & 40 & 1.8 & 2500 & $4.41 \mathrm{E}+10$ & 0.15 \\
\hline K-AB-A & 35 & 1.2 & 2500 & $2.93 \mathrm{E}+10$ & 0.15 \\
\hline K-AB-B & 35 & 1.2 & 2500 & $2.93 \mathrm{E}+10$ & 0.15 \\
\hline K-P-1 & 40 & 1.6 & 2500 & $3.91 \mathrm{E}+10$ & 0.15 \\
\hline K-P-2 & 40 & 1.6 & 2500 & $3.91 \mathrm{E}+10$ & 0.15 \\
\hline
\end{tabular}

The soil strata are divided into six layers. The dimensions are made sure it is efficiently large to ensure it does not affect the result.

Table 3 shows the MDP parameters for all of the FEM models. Cohesion and friction angle is obtained by converting the Mohr-Coulomb parameters to Drucker-Prager parameters. The following equations are used in converting Mohr-Coulomb parameters $\mathrm{c}$ and $\varnothing$ into MDP cap model parameters $d$ and $\beta$ [34]

$$
\begin{gathered}
d=\frac{18 c \cos \varnothing}{3-\sin \varnothing} \\
\tan \beta=\frac{6 c \sin \varnothing}{3-\sin \varnothing}
\end{gathered}
$$

The value for $\mathrm{R}$ is assumed to be 0.4 . Initial strain in the initial stress at the cap hardening curve is zero, thus $\varepsilon_{0}$ is equal to zero. The value for $\alpha$ varies from $0.01-0.05$, and the adopted value is 0.01 . The value for $\mathrm{K}$ can be obtained using the expression [34]

$$
k=\frac{3-\sin \varnothing}{3+\sin \varnothing}
$$

To secure the convexity of the yield surface, the range of $\mathrm{K}$ must be within $0.778-1.0$. The soil friction angle in this study is 32 degrees; if (10) used, this would result in a lesser value than the minimum value for $\mathrm{K}$. Therefore, 0.778 is the adopted value for $\mathrm{K}$.

Table 4 and Table 5 show the regression equations used for obtaining the values of $\mathrm{Cc}$ and $\mathrm{Cs}$, respectively, to obtain the hardening parameter using (7). Most of these regression equations have strong positive correlations applicable for wide types of soils $[25,26,30]$. These equations are applicable for all-natural soils, low plasticity soils, normally-consolidated soils, or clay. It is observed to select appropriate regression equations for the current study to minimize errors and avoid yielding extreme values. Consequentially, the mean values from these equations are taken for the final value of $\mathrm{Cc}$ and $\mathrm{Cs}$ in each soil layer.

The analysis consists of three steps. In the first step, a "body-force" option is used to apply the effective 
self-weight of the soil. The soil is modeled as normally consolidated, and the soil lateral coefficient is taken to be Ko $=1-$ sinø. The second step is an intermediary step between the first and third steps to avoid errors in the analysis computation. In the third step, a loading is applied at the top of the pile. A monotonic loading at a rate of $0.0001 \mathrm{D} \mathrm{mm} / \mathrm{s}$ is forced at the top of the pile to reach the $0.01 \mathrm{D}$ settlement. This slow loading rate elicits a drained loading in the modeling procedure to assimilate an "effective stress" analysis, thus appropriate for highly permeable soils (e.g., sandy soils) [10].

The pile and soil contact surfaces are assumed to be in perfect contact before the load application; this is applied using the "normal behavior" with the "hard" contact option in the software. The tangential interaction between the pile and soil is modeled with friction. A "penalty" interface with no limit shear resistance is adopted. This interface is suitable for representing the friction interaction between the pile and the soil [11]. Thus, the activation of skin resistance adds a shear resistance to the lateral surface of the pile. This shear force depends on the value of the coefficient of friction and normal forces, as shown in Fig. 4.

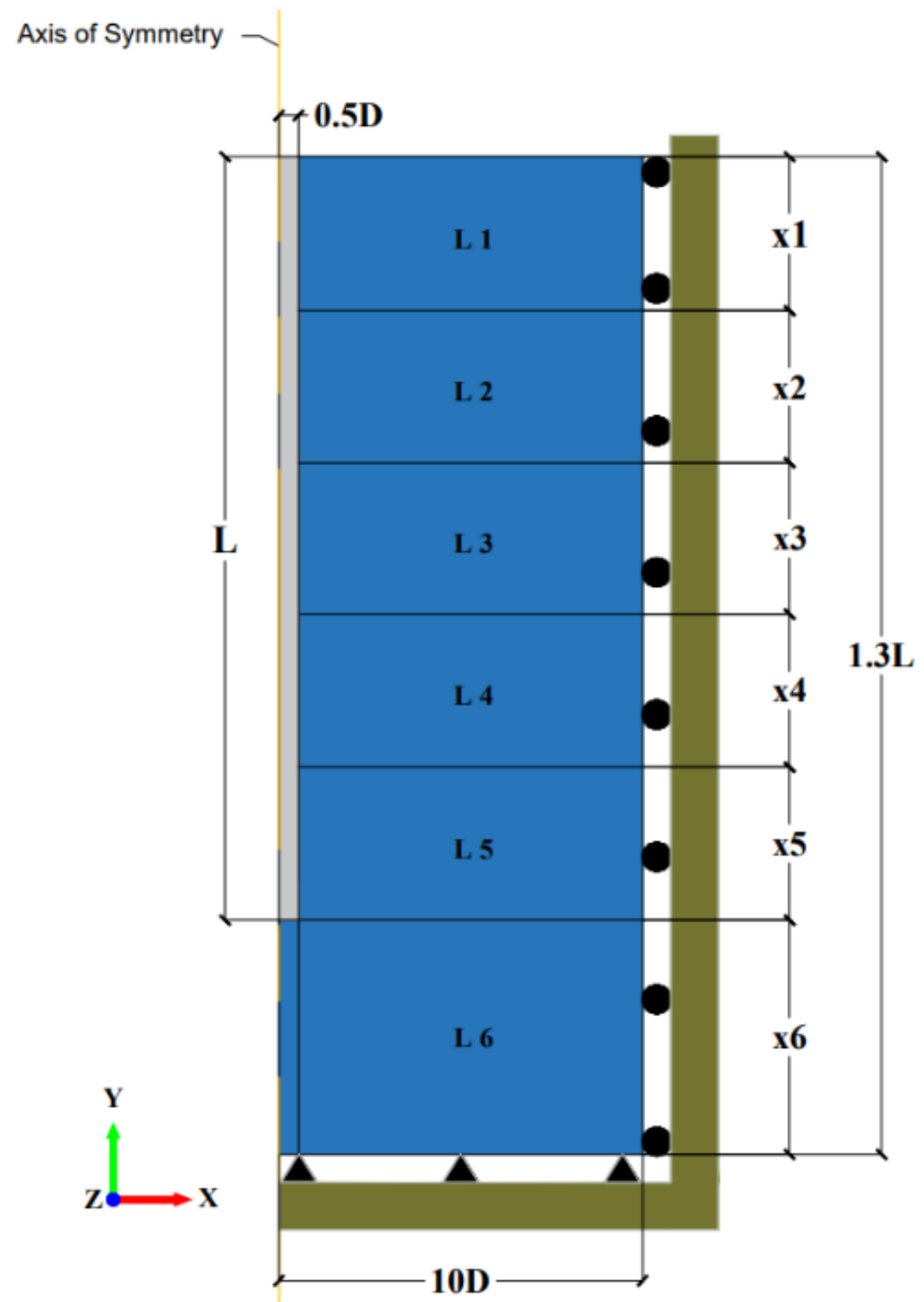

Figure 3. Model Dimensions and Boundary Conditions 
Table 2. FEM Soil Material Properties

\begin{tabular}{|c|c|c|c|c|c|c|c|c|c|c|}
\hline Layer & Depth (m) & $e_{0}$ & $k(m / s)$ & $w \%$ & ø (degrees) & $\gamma_{\text {sat }}\left(\mathrm{KN} / \mathrm{m}^{3}\right)$ & $E_{s}(\mathrm{~Pa})$ & $v$ & $\mathrm{Cc}$ & Cs \\
\hline \multicolumn{11}{|c|}{ O-AB-A } \\
\hline L1 & $1-6$ & 0.71 & \multirow{6}{*}{$1 \times 10^{-6}$} & 26.80 & \multirow{6}{*}{32} & 18.41 & $3.72 \mathrm{E}+07$ & \multirow{6}{*}{0.20} & 0.19 & 0.03 \\
\hline $\mathrm{L} 2$ & $6-12$ & 0.61 & & 22.75 & & 18.46 & $3.03 \mathrm{E}+07$ & & 0.14 & \multirow{5}{*}{0.02} \\
\hline L3 & $12-18$ & \multirow{2}{*}{0.56} & & 21.00 & & \multirow{4}{*}{18.85} & \multirow{4}{*}{$6.00 \mathrm{E}+07$} & & 0.13 & \\
\hline L4 & $18-24$ & & & 20.75 & & & & & \multirow{3}{*}{0.12} & \\
\hline L5 & $24-30$ & \multirow{2}{*}{0.55} & & \multirow{2}{*}{20.50} & & & & & & \\
\hline L6 & $30-36$ & & & & & & & & & \\
\hline \multicolumn{11}{|c|}{ O-AB-B } \\
\hline L1 & $1-6$ & 0.53 & \multirow{6}{*}{$1 \times 10^{-6}$} & 20.00 & \multirow{6}{*}{32} & 18.72 & $3.47 \mathrm{E}+07$ & & \multirow{2}{*}{0.11} & \\
\hline L2 & $6-12$ & 0.52 & & 19.50 & & 18.85 & $2.93 \mathrm{E}+07$ & & & \\
\hline L3 & $12-18$ & 0.55 & & 20.50 & & & & 020 & 0.12 & 002 \\
\hline L4 & $18-24$ & 0.50 & & 18.75 & & 1885 & $600 \mathrm{~F}+07$ & 0.20 & 0.10 & 0.02 \\
\hline L5 & $24-30$ & 0.52 & & 1950 & & 18.85 & $0.00 \mathrm{CTO}$ & & & \\
\hline L6 & $30-39$ & 0.52 & & 19.50 & & & & & 0.11 & \\
\hline & & & & & O-P-1 & & & & & \\
\hline L1 & $1-7.5$ & 0.58 & & 21.71 & & 18.69 & $3.24 \mathrm{E}+07$ & & 013 & 0.02 \\
\hline L2 & $7.5-16.5$ & 0.58 & & 21.50 & & & $6.00 \mathrm{E}+07$ & & $0.1 \mathrm{~J}$ & 0.02 \\
\hline L3 & $16.5-25.5$ & 0.62 & & 23.17 & 32 & & $5.53 \mathrm{E}+07$ & 020 & 0.15 & 0.03 \\
\hline L4 & $25.5-33$ & 0.57 & $1 \times 10$ & 21.20 & 52 & 18.85 & & 0.20 & 0.13 & \\
\hline L5 & $33-40.5$ & 054 & & 2000 & & & $6.00 \mathrm{E}+07$ & & 011 & 0.02 \\
\hline L6 & $40.5-52$ & 0.84 & & 20.00 & & & & & 0.11 & \\
\hline & & & & & O-P-2 & & & & & \\
\hline L1 & $1-7.5$ & 0.52 & & 19.57 & & 18.74 & $4.01 \mathrm{E}+07$ & & 0.11 & \\
\hline $\mathrm{L} 2$ & $7.5-16.5$ & 0.54 & & 20.33 & & & $590 \mathrm{~F}+07$ & & 0.12 & \\
\hline L3 & $16.5-25.5$ & 0.54 & & 20.17 & & & 5.900701 & 0.20 & 0.12 & 0.02 \\
\hline L4 & $25.5-33$ & 0.59 & $1 \times 10^{-6}$ & 22.20 & 32 & 18.85 & & 0.20 & 0.14 & 0.02 \\
\hline L5 & $33-40$ & 0.56 & & 21.00 & & & $6.00 \mathrm{E}+07$ & & & \\
\hline L6 & $40-52$ & & & & & & & & 0.13 & \\
\hline & & & & & K-AB-A & & & & & \\
\hline L1 & $1-7.5$ & 0.82 & & 24.86 & & 18.58 & $3.31 \mathrm{E}+07$ & & 0.20 & 0.03 \\
\hline $\mathrm{L} 2$ & $7.5-13.5$ & 0.55 & & 20.75 & & & $4.08 \mathrm{E}+07$ & & 0.12 & \\
\hline L3 & $13.5-21$ & 0.50 & $10^{-6}$ & 18.80 & 32 & & $5.12 \mathrm{E}+07$ & 020 & 0.10 & \\
\hline L4 & $21-28.5$ & 0.52 & $1 \times 10$ & 19.60 & 32 & 18.85 & $5.66 \mathrm{E}+07$ & 0.20 & 0.11 & 0.02 \\
\hline L5 & $28.5-35$ & 062 & & 2300 & & & $600 \mathrm{~F}+07$ & & 0.15 & \\
\hline L6 & $35-45.5$ & 0.02 & & 25.00 & & & $0.00 \mathrm{~L} 107$ & & 0.15 & \\
\hline & & & & & K-AB-B & & & & & \\
\hline L1 & $1-7.5$ & 0.84 & & 26.86 & & 18.58 & $3.14 \mathrm{E}+07$ & & 0.22 & 003 \\
\hline $\mathrm{L} 2$ & $7.5-13.5$ & 0.65 & & 24.50 & & & $5.55 \mathrm{E}+07$ & & 0.16 & 0.03 \\
\hline L3 & $13.5-21$ & 0.55 & & 20.40 & & & $5.78 \mathrm{E}+07$ & 0.20 & 0.12 & 002 \\
\hline L4 & $21-28.5$ & 0.53 & $1 \times 10^{-6}$ & 19.60 & 32 & 18.85 & $5.72 \mathrm{E}+07$ & 0.20 & 0.11 & 0.02 \\
\hline L5 & $28.5-35$ & & & & & & & & & \\
\hline L6 & $35-45.5$ & 0.66 & & 24.75 & & & $6.00 \mathrm{E}+07$ & & 0.17 & 0.03 \\
\hline & & & & & K-P-1 & & & & & \\
\hline L1 & $1-7.5$ & 0.64 & & 23.86 & & & $4.26 \mathrm{E}+07$ & & 0.16 & 0.03 \\
\hline $\mathrm{L} 2$ & $7.5-16.5$ & 0.58 & & 21.50 & & & $5.55 \mathrm{E}+07$ & & 0.13 & \\
\hline L3 & $16.5-25.5$ & 0.50 & & 18.83 & 32 & 1885 & $5.70 \mathrm{E}+07$ & 020 & 0.10 & \\
\hline L4 & $25.5-33$ & 0.48 & $1 \times 10$ & 17.80 & 32 & 10.85 & $5.72 \mathrm{E}+07$ & 0.20 & 0.12 & 0.02 \\
\hline L5 & $33-40.5$ & 054 & & 2000 & & & $5.96 \mathrm{E}+07$ & & 0.12 & \\
\hline L6 & $40.5-52$ & 0.54 & & 20.00 & & & $5.90 E+01$ & & 0.11 & \\
\hline & & & & & K-P-2 & & & & & \\
\hline L1 & $1-7.5$ & 0.82 & & 30.71 & & 18.36 & $3.00 \mathrm{E}+07$ & & 0.23 & 0.04 \\
\hline $\mathrm{L} 2$ & $7.5-16.5$ & 0.56 & & 21.00 & & & $5.28 \mathrm{E}+07$ & & 0.13 & \\
\hline L3 & $16.5-25.5$ & 0.54 & & 20.00 & & & $5.43 \mathrm{E}+07$ & & 0.11 & \\
\hline L4 & $25.5-33$ & 0.47 & $1 \times 10^{-6}$ & 17.60 & 32 & 18.85 & $5.92 \mathrm{E}+07$ & 0.20 & 0.12 & 0.02 \\
\hline L5 & $33-40.5$ & 0.49 & & 18.20 & & & $\mathrm{E}+07$ & & 0.11 & \\
\hline L6 & $40.5-52$ & 0.49 & & 1 & & & $5.94 \mathrm{E}+01$ & & 0.11 & \\
\hline
\end{tabular}


Table 3. Modified Drucker Prager Parameters

\begin{tabular}{|c|c|}
\hline Cohesion, $d$ & 0 \\
\hline Angle of friction, $\beta$ & 52.16 \\
\hline Cap Eccentricity, $\mathrm{R}$ & 0.4 \\
\hline Initial Yield surface position, $\boldsymbol{\varepsilon}_{\boldsymbol{o}}$ & 0 \\
\hline Transition surface radius, $\alpha$ & 0.01 \\
\hline Flow stress ratio, $\mathrm{K}$ & 0.778 \\
\hline
\end{tabular}

Table 4. Compression Index (Cc) Regression Equations

\begin{tabular}{|c|c|c|}
\hline Regression & Applicability & Reference \\
\hline \multicolumn{3}{|c|}{$w(\%)$ as parameter } \\
\hline $0.0064(\mathrm{w})-0.0607$ & \multirow{2}{*}{ All natural soils } & [31] \\
\hline $0.013(w)-0.115$ & & {$[30]$} \\
\hline $0.012(w)-0.086$ & \multirow{2}{*}{ Low Plasticity soils } & \multirow{2}{*}{ [27] } \\
\hline $0.326 \ln (w)-0.838$ & & \\
\hline $0.012(w)-0.098$ & Normally consolidated soils & [27] \\
\hline $0.012(w)-0.1$ & \multirow{3}{*}{ All natural soils } & \multirow{3}{*}{ [27] } \\
\hline $0.479 \ln (w)-1.367$ & & \\
\hline$e^{[1.235 \ln (w)-5.65]}$ & & \\
\hline $0.01(w-5)$ & All-natural soils & [26] \\
\hline \multicolumn{3}{|c|}{$e_{0}$ as parameter } \\
\hline $0.2213 \boldsymbol{e}_{0}-0.0171$ & \multirow{7}{*}{ All natural soils } & \multirow{4}{*}{ [31] } \\
\hline $0.1673 \boldsymbol{e}_{\mathbf{0}}-0.0112$ & & \\
\hline $0.2055 \boldsymbol{e}_{\mathbf{0}}+0.0041$ & & \\
\hline $0.2945 \boldsymbol{e}_{\mathbf{0}}-0.0649$ & & \\
\hline$e^{\left[1.272 \ln \left(e_{0}\right)-1.282\right]}$ & & \multirow{3}{*}{ [27] } \\
\hline $0.40 \boldsymbol{e}_{0}-0.10$ & & \\
\hline $\left.0.485 \ln \left(\boldsymbol{e}_{\mathbf{0}}\right)+0.329\right)$ & & \\
\hline$e^{\left[1.43 \ln \left(e_{0}\right)-1.19\right]}$ & \multirow{3}{*}{ Low Plasticity soils } & \multirow{3}{*}{ [27] } \\
\hline $0.407 \boldsymbol{e}_{0}-0.094$ & & \\
\hline $0.317+0.338 \ln \left(\boldsymbol{e}_{\mathbf{0}}\right)$ & & \\
\hline $0.43 \boldsymbol{e}_{\mathbf{0}}-0.122$ & Normally consolidated soils & [27] \\
\hline $0.40\left(\boldsymbol{e}_{\mathbf{0}}+0.001 w-0.25\right)$ & All natural soils & [26] \\
\hline
\end{tabular}

Table 5. Swelling Index (Cs) Regression Equations

\begin{tabular}{|c|c|c|}
\hline Regression EQ. & Applicability & Reference \\
\hline \multicolumn{3}{|c|}{$w(\%)$ as parameter } \\
\hline $0.0025 \mathrm{w}-0.0405$ & All natural soils & [31] \\
\hline $0.00087 \mathrm{w}$ & \multirow{2}{*}{ Clay } & [29] \\
\hline $0.0133 \boldsymbol{e}^{\mathbf{0 . 0 3 6 w}}$ & & {$[28]$} \\
\hline \multicolumn{3}{|c|}{$e_{0}$ as parameter } \\
\hline $0.0856 \boldsymbol{e}_{\mathbf{0}}-0.0226$ & All natural soils & [31] \\
\hline $0.0121 e^{1.3131 * e_{0}}$ & Clay & {$[28]$} \\
\hline
\end{tabular}




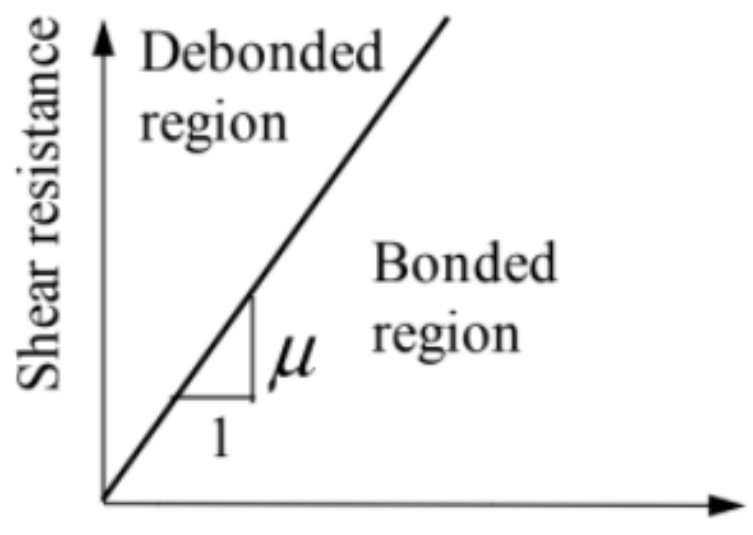

\section{Normal stress}

Figure 4. Shear vs. Normal resistance: No Resistance Limit for Shear

The coefficient of friction is obtained through the Mohr-Coulomb friction model, $\mu=\tan \delta$ and $\delta$ is taken as equal to $0.75 \varnothing^{\prime}$ for concrete piles [18].

Two types of mesh are adopted in each model to determine the difference in accuracy between a finer and coarser mesh. Tables 6 and 7 show the sizes of the seeds of the mesh and the number of elements of each model. The seed sizes in Table 6 produce a relatively finer mesh and a higher number of elements than the seed sizes in Table 7.

Table 6. Mesh Sizes - A (FEM-A)

\begin{tabular}{|c|c|c|c|c|c|c|}
\hline \multirow{4}{*}{ Model } & \multicolumn{5}{|c|}{ Seed Sizes } & \multirow{4}{*}{$\begin{array}{l}\text { Total No. of } \\
\text { ELEMENTS }\end{array}$} \\
\hline & \multicolumn{2}{|c|}{ Pile } & \multicolumn{3}{|c|}{ Soil } & \\
\hline & \multirow{2}{*}{$\begin{array}{c}\text { Horizontal (no. } \\
\text { of elements) }\end{array}$} & \multirow{2}{*}{$\begin{array}{l}\text { Vertical (Apprx. } \\
\text { Element Size) }\end{array}$} & \multicolumn{2}{|c|}{ Horizontal } & \multirow{2}{*}{$\begin{array}{l}\text { Vertical (Apprx. } \\
\text { Element Size) }\end{array}$} & \\
\hline & & & $\operatorname{Max}$ & Min & & \\
\hline O-AB-A & 3 & 1.0 & 1.8 & 0.2 & 1.0 & 819 \\
\hline O-AB-B & 3 & 1.0 & 1.8 & 0.2 & 1.0 & 819 \\
\hline O-P-1 & 3 & 1.3 & 2 & 0.3 & 1.3 & 880 \\
\hline O-P-2 & 3 & 1.3 & 2 & 0.3 & 1.3 & 880 \\
\hline K-AB-A & 3 & 1.0 & 2 & 0.2 & 1.0 & 810 \\
\hline K-AB-B & 3 & 1.0 & 2 & 0.2 & 1.0 & 810 \\
\hline K-P-1 & 3 & 1.3 & 1.8 & 0.3 & 1.3 & 840 \\
\hline K-P-1 & 3 & 1.3 & 1.8 & 0.3 & 1.3 & 840 \\
\hline
\end{tabular}

Table 7. Mesh Sizes - B (FEM-B)

\begin{tabular}{|c|c|c|c|c|c|c|}
\hline \multirow{4}{*}{ Model } & \multicolumn{5}{|c|}{ Seed Sizes } & \multirow{4}{*}{$\begin{array}{l}\text { Total No. of } \\
\text { ELEMENTS }\end{array}$} \\
\hline & \multicolumn{2}{|c|}{ Pile } & \multicolumn{3}{|c|}{ Soil } & \\
\hline & \multirow{2}{*}{$\begin{array}{c}\text { Horizontal (no. } \\
\text { of elements) }\end{array}$} & \multirow{2}{*}{$\begin{array}{c}\text { Vertical } \\
\text { (Apprx. } \\
\text { Element Size) }\end{array}$} & \multicolumn{2}{|c|}{ Horizontal } & \multirow{2}{*}{$\begin{array}{l}\text { Vertical (Apprx. } \\
\text { Element Size) }\end{array}$} & \\
\hline & & & Max & Min & & \\
\hline O-AB-A & 2 & 1.5 & 4 & 0.4 & 1.5 & 260 \\
\hline O-AB-B & 2 & 1.5 & 4 & 0.4 & 1.5 & 260 \\
\hline O-P-1 & 2 & 2 & 6.5 & 0.4 & 2 & 248 \\
\hline O-P-2 & 2 & 2 & 6.5 & 0.4 & 2 & 248 \\
\hline K-AB-A & 2 & 1.7 & 4 & 0.4 & 1.7 & 236 \\
\hline K-AB-B & 2 & 1.7 & 4 & 0.4 & 1.7 & 236 \\
\hline K-P-1 & 2 & 2 & 5.5 & 0.4 & 2 & 248 \\
\hline K-P-1 & 2 & 2 & 5.5 & 0.4 & 2 & 248 \\
\hline
\end{tabular}


All horizontal edges of the soil geometry are chosen using the "single" bias except those below the pile. A single-bias seeding generates an increasing amount of elements in the chosen direction. The direction of "maximum" to "minimum" seed size points towards the pile since high stresses and displacements are more active in this direction during loading.

In contrast, a "none" bias option is applied to vertical edges of pile and soil geometry. This option distributes equal seed sizes. Also, the number of horizontal elements beneath the pile tip is equal to the horizontal elements of the pile.

Data for the load-settlement curve is obtained from the results of FEM analysis. The double-tangent method determines the ultimate capacity Qu: the magnitude of load at the curve's intersection with the vertical line intersecting the intersection of two tangent lines drawn on the load-settlement curve [2].

Settlement at the ultimate capacity is obtained and inputted for another analysis to determine the skin friction resistance Qs and pile base resistance $\mathrm{Qb}$. The Qs are determined by subtracting the soil pressure from the pile tip to the Qu.

Results for $\mathrm{Qu}, \mathrm{Qs}$, and $\mathrm{Qb}$ were compared with the PDA test results. The PDA data were analyzed using CAPWAP software for more accurate results of ultimate capacity. Results from analytical methods for cohesionless soils, e.g., Meyerhof (1976), Coyle \& Castello (1981), and Beta method, were also used to determine $\mathrm{Qu}$ as a summation of $\mathrm{Qb}$ and Qs and compared to the results of in-situ results for comparative analysis. Table 8 shows the equations of these analytical methods.

Table 8. Analytical Methods for Cohesionless Soils

\begin{tabular}{|c|c|c|}
\hline Method & $\begin{array}{c}\text { Skin Friction } \\
\text { Resistance }\end{array}$ & $\begin{array}{c}\text { Point Bearing } \\
\text { Resistance }\end{array}$ \\
\hline Meyerhof & $\begin{array}{c}\mathrm{Qs}=\Sigma(\pi D \Delta L) \mathrm{Ko} \\
\sigma_{v}^{\prime} \tan \delta\end{array}$ & $\begin{array}{c}\mathrm{Qp}=\frac{\pi}{4} D^{2} q^{\prime} N_{q}^{*[35]} \\
\frac{\pi}{4} D^{2} \mathrm{ql} \\
\mathrm{ql}=\mathrm{pa} N_{q}^{*[35]} \tan (\varnothing)\end{array}$ \\
\hline $\begin{array}{c}\text { Coyle \& } \\
\text { Castello }\end{array}$ & $\begin{array}{c}\mathrm{Qs}=(\pi D L) \mathrm{Ko} \sigma_{\text {ave }}^{\prime} \tan \\
(0.8 \varnothing)\end{array}$ & $\mathrm{Qp}=\frac{\pi}{4} D^{2} q^{\prime} N_{q}^{*[33]}$ \\
\hline Beta & $\begin{array}{c}\mathrm{Qs}=\Sigma(\pi D \Delta L) \mathrm{Ko} \\
\sigma_{v}^{\prime} \tan (0.75 \varnothing)\end{array}$ & $\mathrm{Qp}=\frac{\pi}{4} D^{2} q^{\prime} N_{q}^{[36]}$ \\
\hline
\end{tabular}

Using Micro-Excel, a simple linear regression analysis was conducted to evaluate the performance and significance of the FEM and analytical methods' results.
Moreover, the average percentage errors are determined to determine the difference in the accuracy of the FEM results and the results of the analytical method against the in-situ results.

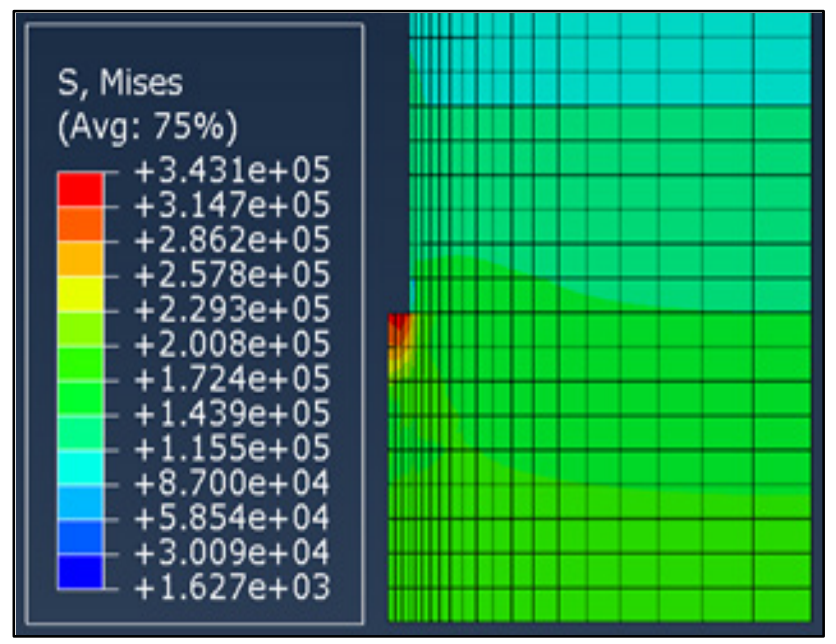

Figure 5. Pile Base Resistance result from FEM analysis

\section{Results and Discussions}

The theoretical volumetric plastic strain (cap hardening) curves of the soil layers are shown in Fig. 6 to 9. It presents the cap hardening behavior of soil layers used in conjunction with the MDP cap model. This model allows soil elements subjected to compressive stress to continuously yield without fracture until the maximum stress in the curves corresponding to the 0.12 strain has reached. Moreover, the analyses show that the maximum strain in the hardening curve models was sufficient to allow the pile to settle at $0.10 \mathrm{D} \mathrm{mm}$ for gathering a pile-load settlement curve.

The curves show that the incremental strain increases as the stresses increase. As the strain progresses, a more significant amount of cumulative stress is required to induce an incremental strain, hence, the positive-increasing behavior of the curves. A relatively higher amount of stress is required to induce a plastic strain in most deeper layers (e.g., L4 to L6)-allowing the deeper layers to deform continuously at higher stresses than layers L1 to L3. 


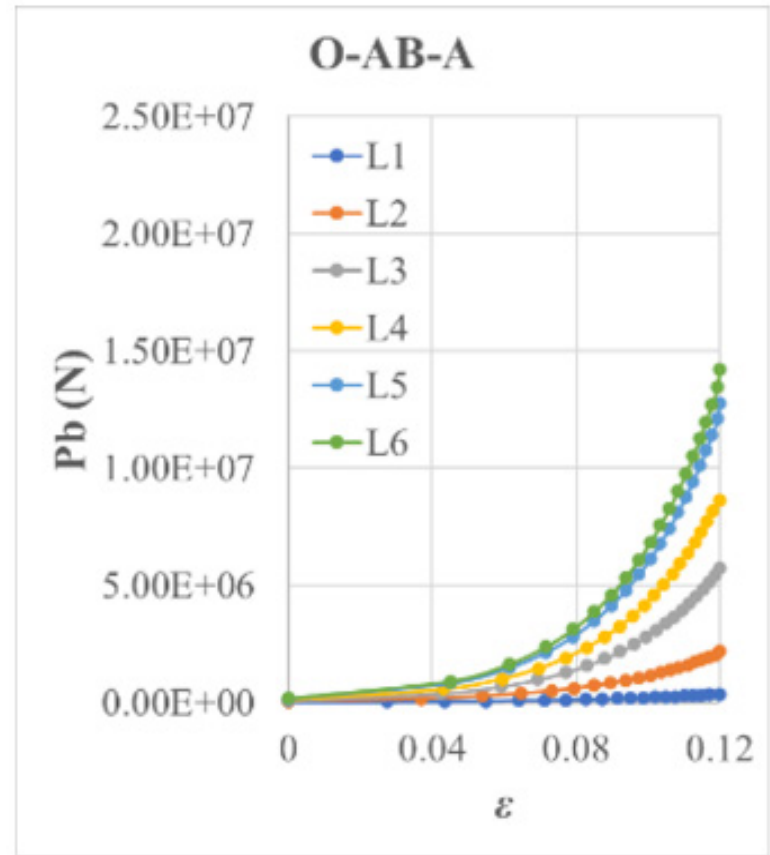

A

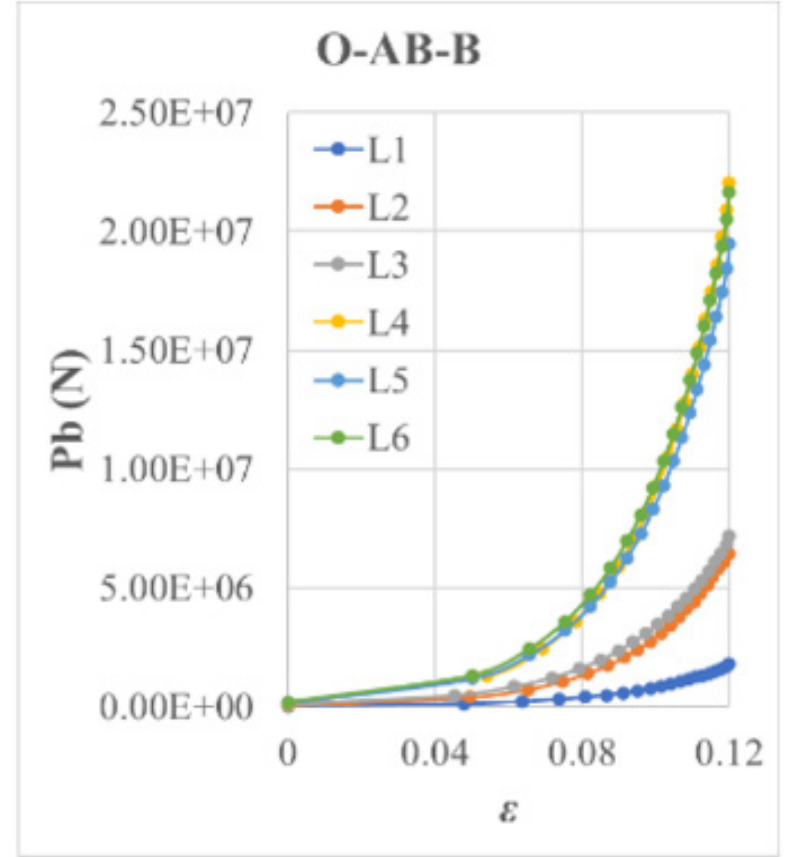

B

Figure 6. Cap Hardening Curves for Each Layers: A) O-AB-A \& B) O-AB-B

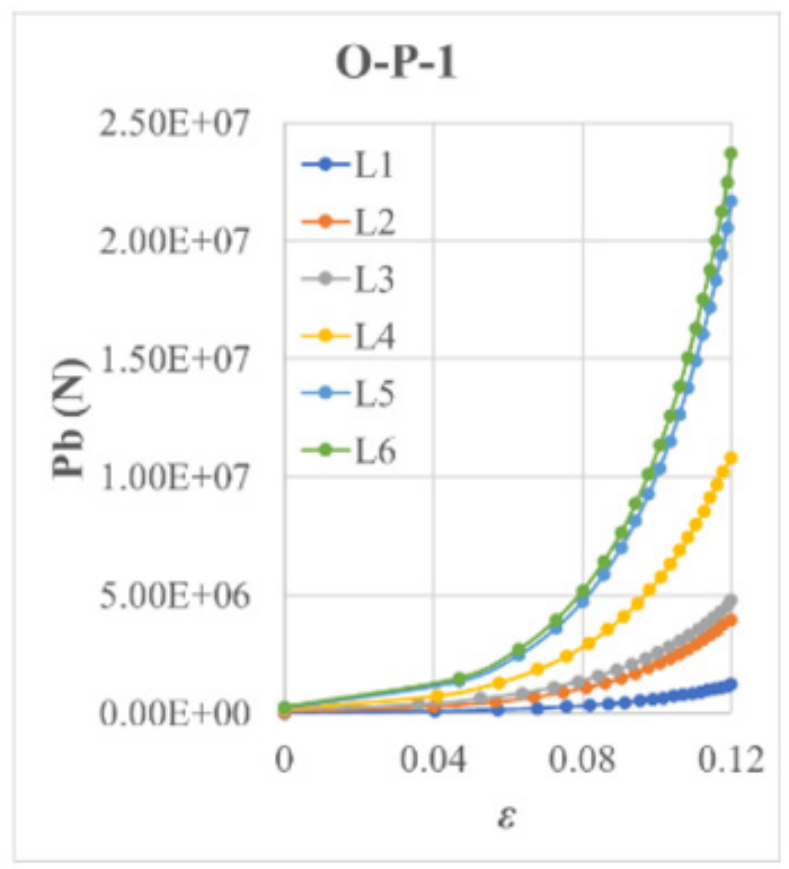

A

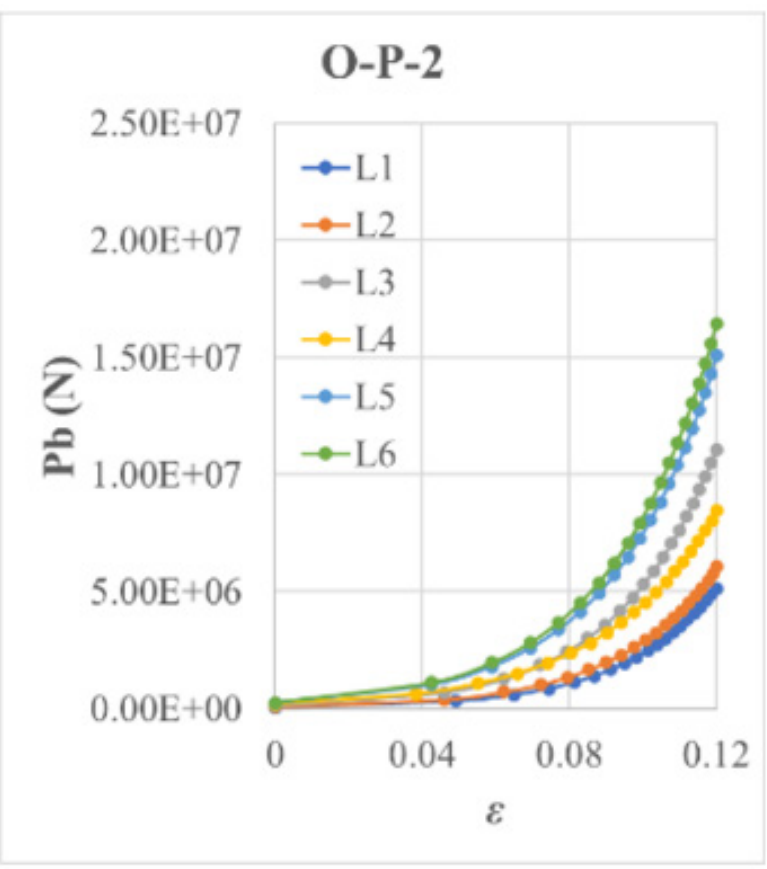

B

Figure 7. Cap Hardening Curves for Each Layers: A) O-P-1 \& B) O-P-2 


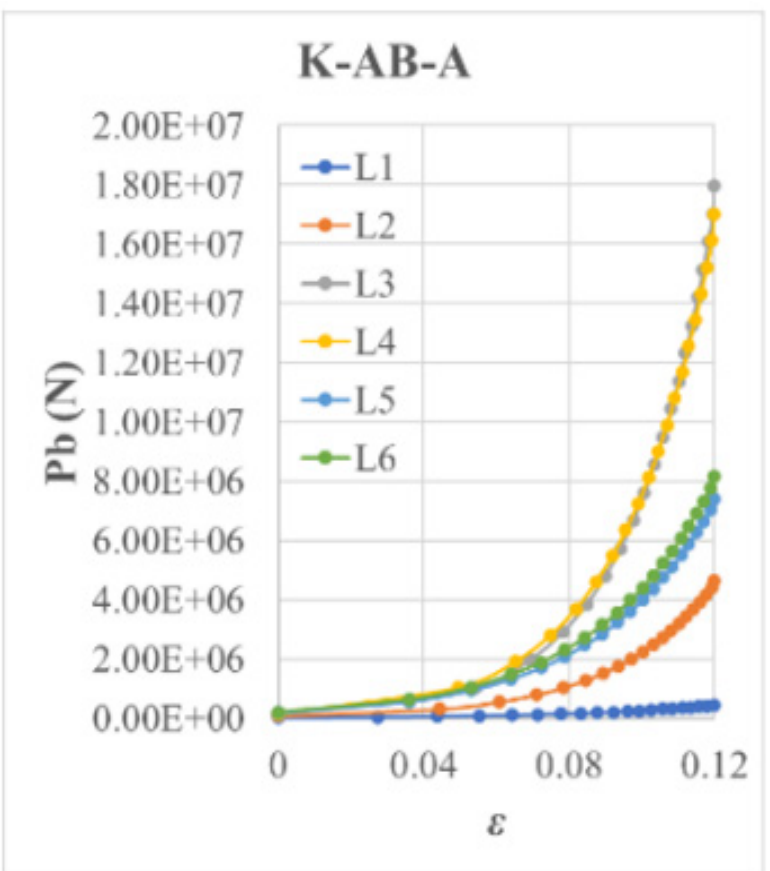

A

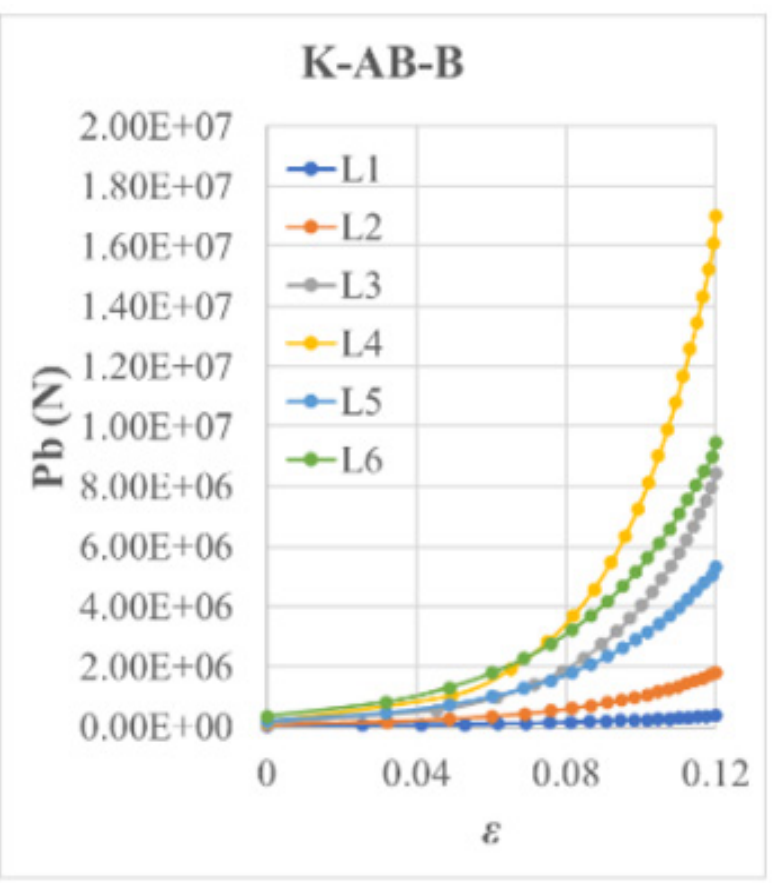

B

Figure 8. Cap Hardening Curves for Each Layers: A) K-AB-A \& B) K-AB-B

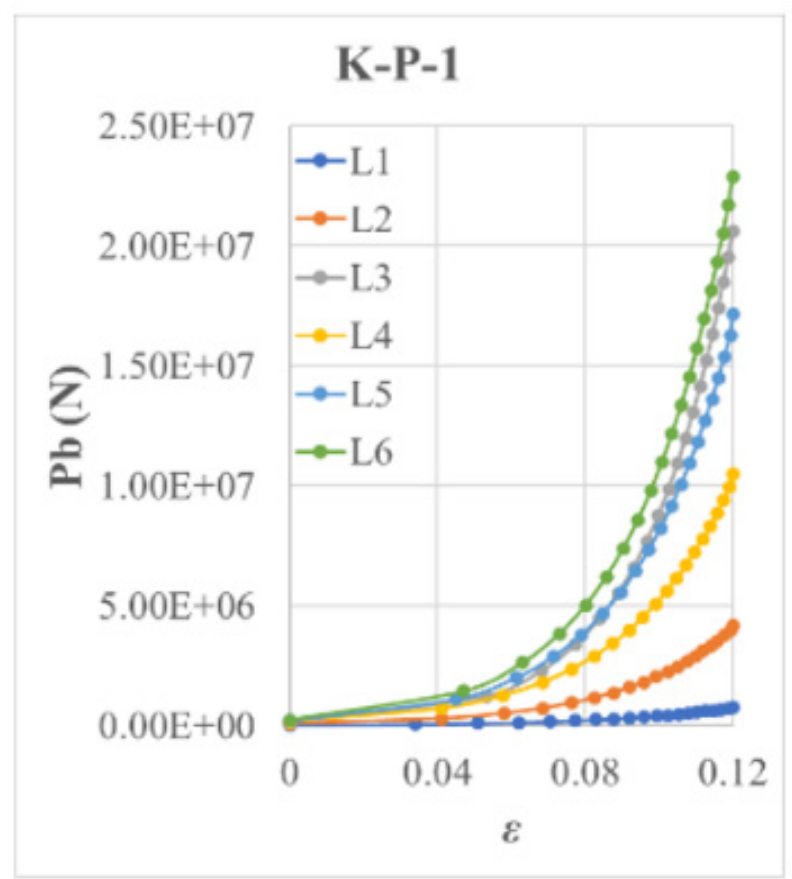

A

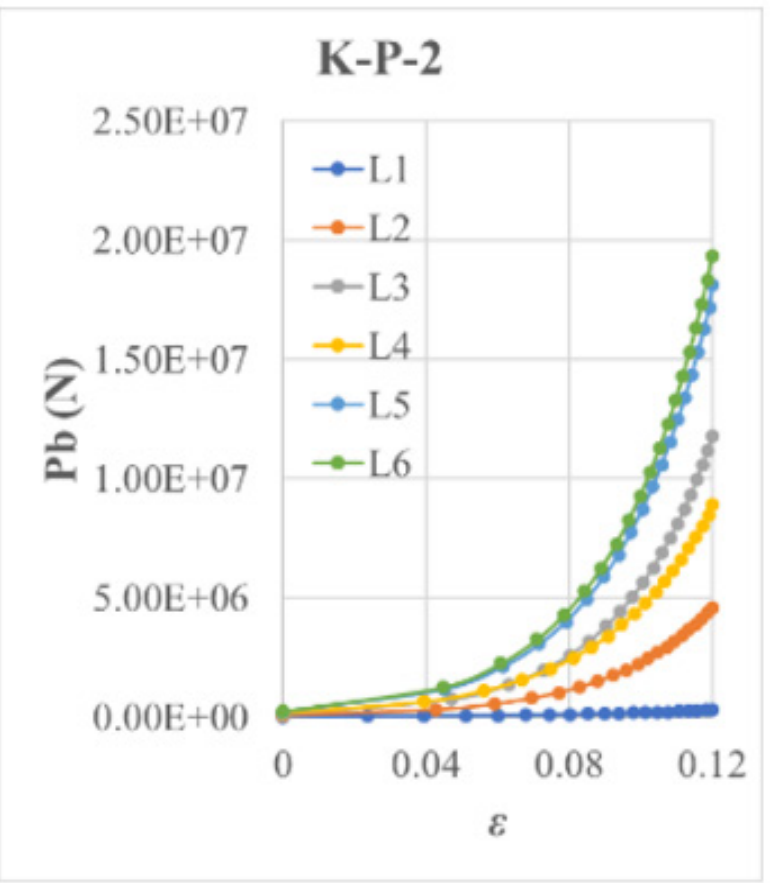

B

Figure 9. Cap Hardening Curves for E

\subsection{Load Settlement Curves and Ultimate Capacities}

Fig. 10 and 11 show the load settlement curves and the ultimate capacity of the FEM models. Fig. 10 shows the results using mesh-A (FEM-A), and the latter, Fig. 11, are the results using mesh-B (FEM-B). The two figures show that the ultimate capacities of the same piles but different meshes have insignificant differences. 
Fig. 12, 13, and 14 show the resistance values comparison between the FEM and analytical methods' results against the PDA/CAPWAP results. It is observed that the ultimate capacities from the FEM models have conservative values compared to the in-situ results. Table 9 shows the statistical results. The correlation coefficients range from $0.51-0.62,0.5-0.58$, and $0.45-0.5$ for $\mathrm{Qu}, \mathrm{Qs}$, and $\mathrm{Qb}$, respectively.

These values indicate a moderate positive correlation for $\mathrm{Qu}$ and Qs and a low to moderate positive correlation for $\mathrm{Qb}$. The $\mathrm{F}$ and T statistics are less than the $f_{\text {crit }}$ (5.99) and $t_{c r i t}(2.45)$ and the values of $p_{v a l}$ is greater than the significance level 0.05 , indicating that the results of the FEM and analytical methods were insignificant [35].

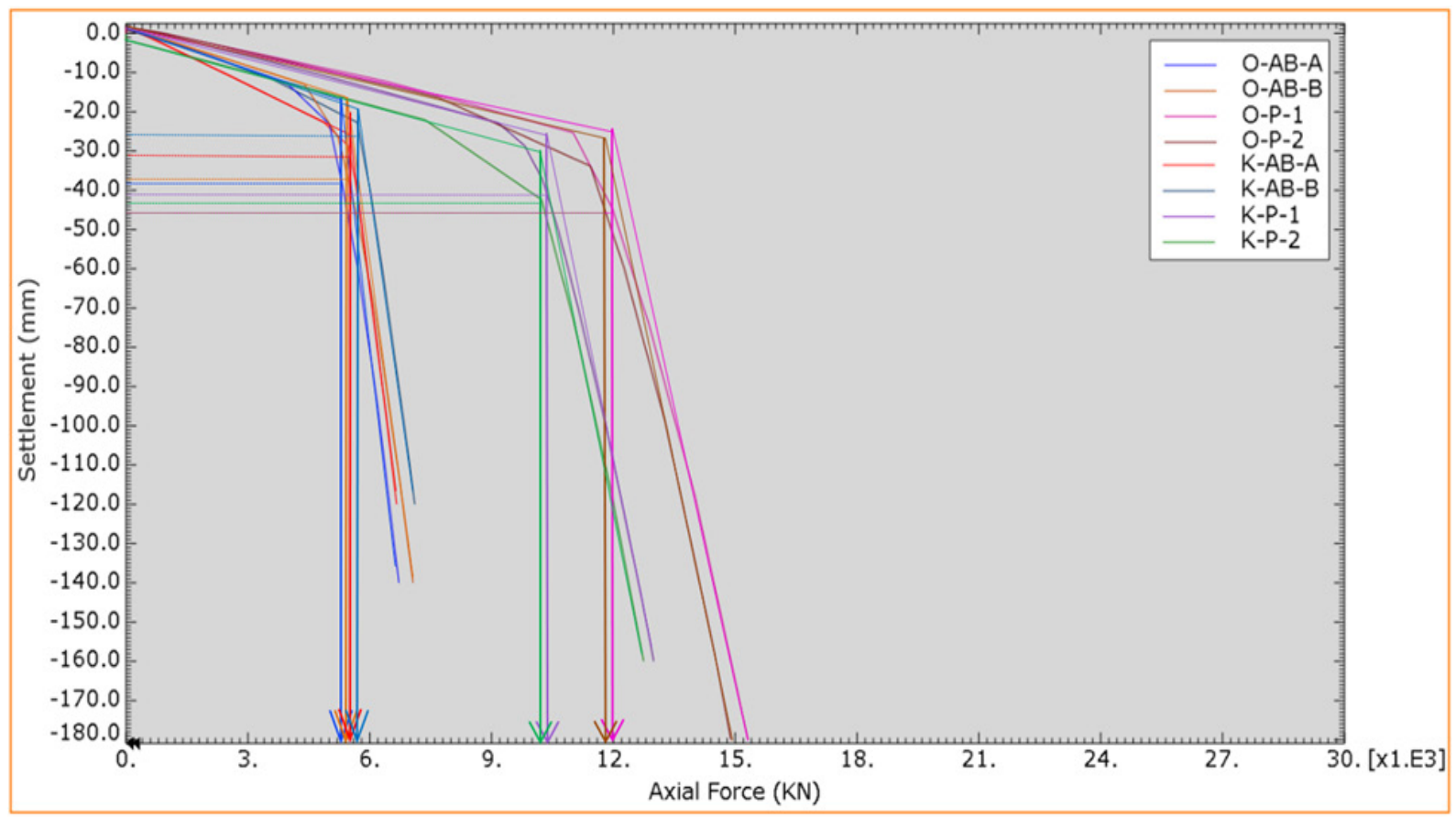

Figure 10. FEM-A: Load vs. Settlement Curves

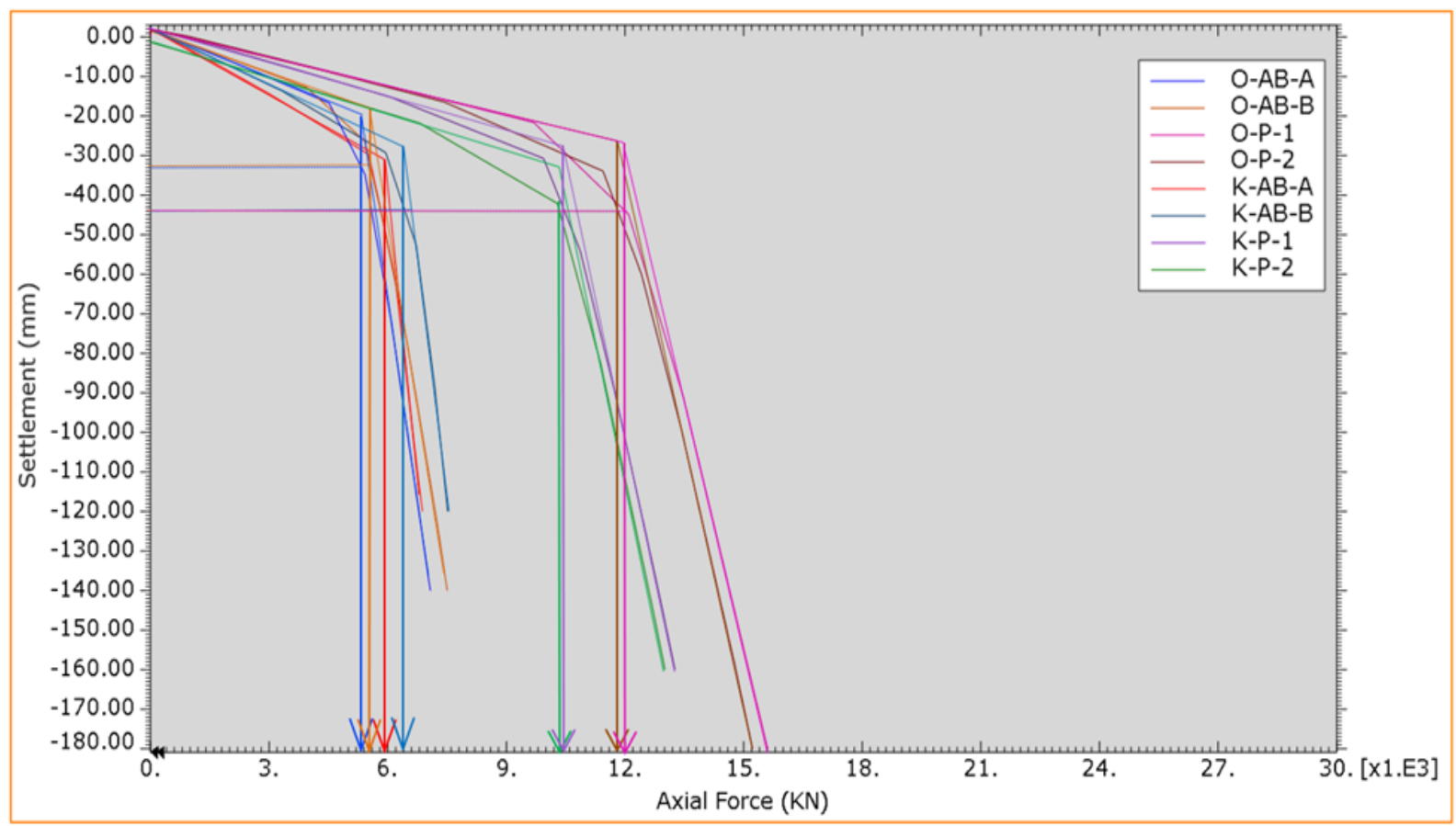

Figure 11. FEM-B: Load vs. Settlement Curves 
The Coyle \& Castello method has the highest correlation coefficient in $\mathrm{Qu}$ values with $\mathrm{R}=0.62$ followed by the Meyerhof $(\mathrm{R}=0.61)$, Beta $(\mathrm{R}=0.59)$, FEM-A $(\mathrm{R}=0.58)$ and FEM-B $(\mathrm{R}=0.51)$. Ultimate capacity results of FEM-A have the least standard error and average percentage error with values of $\mathrm{SE}=2685 \mathrm{KN}$ and Ave $\%$ Err. $=23 \%$; and from the least, these are followed by FEM-B ( $\mathrm{SE}=2880 \mathrm{KN}$, Ave $\%$ Err. $=25 \%)$, Beta method $(\mathrm{SE}=5205 \mathrm{KN}$, Ave $\%$ Err. $=47 \%)$, and Coyle \& Castello method $(\mathrm{SE}=11579 \mathrm{KN}$, Ave $\%$ Err. $=190 \%)$.

In Qs values, the Coyle \& Castello method has the highest correlation coefficient with $\mathrm{R}=0.58$, followed by the FEM-A $(\mathrm{R}=0.52)$, Meyerhof and Beta $(\mathrm{R}=0.5)$, and FEM-B $(\mathrm{R}=0.44)$. Meyerhof and Beta method have the least standard error with $\mathrm{SE}=2206 \mathrm{KN}$, followed by FEM-A (SE = $2588 \mathrm{KN})$, FEM-B $(\mathrm{SE}=2746 \mathrm{KN})$, and Coyle and Castello ( $\mathrm{SE}=3757 \mathrm{KN})$. FEM-A and FEM-B have the least average percentage error (Ave $\%$ Err. $=23 \%$ ), followed by Meyerhof and Beta (Ave $\%$ Err. $=35 \%)$, and Coyle \& Castello (Ave $\%$ Err. $=27 \%$ ).

In the point bearing resistance results, the results of FEM-A have the highest correlation coefficient in the $\mathrm{Qb}$ values with $R=0.54$ followed by the Meyerhof $(R=0.50)$,
Coyle \& Castello $(\mathrm{R}=0.47)$, Beta $(\mathrm{R}=0.45)$ and FEM-B $(\mathrm{R}=0.43)$. FEM-B have the least error values with $\mathrm{SE}=$ $259 \mathrm{KN}$ and Ave $\%$ Err. $=38 \%$ followed by FEM-A $(\mathrm{SE}=$ $270 \mathrm{KN}$, Ave $\%$ Err. = 41\%) Meyerhof $(\mathrm{SE}=1338 \mathrm{KN}$, Ave $\%$ Err. $=454 \%)$, Beta $(\mathrm{SE}=3509 \mathrm{KN}$, Ave $\%$ Err. $=$ $890 \%$ ) and Coyle \& Castello (SE $=9049 \mathrm{KN}$, Ave\%Err. $=$ $2395 \%)$

Results from the FEM models for $\mathrm{Qu}, \mathrm{Qs}$, and $\mathrm{Qb}$ consistently have lower standard errors and average percentage errors. The Meyerhof method has the least SE and Ave \%Err., followed by the Beta method and Coyle $\&$ Castello method among the analytical methods. Qs have no significant differences in SE and Ave\%Err., among FEM and analytical methods.

However, relatively significant differences are observed for the $\mathrm{Qb}$ values. The FEM has the least errors for $\mathrm{Qb}$ values, followed by the Meyerof method and Beta method. In contrast, the Coyle and Castello method has the most significant error values.

Furthermore, the statistical results of FEM-A are moderately superior to the FEM-B models. These findings indicate that finer mesh models have better performance than models that have a relatively coarser mesh.

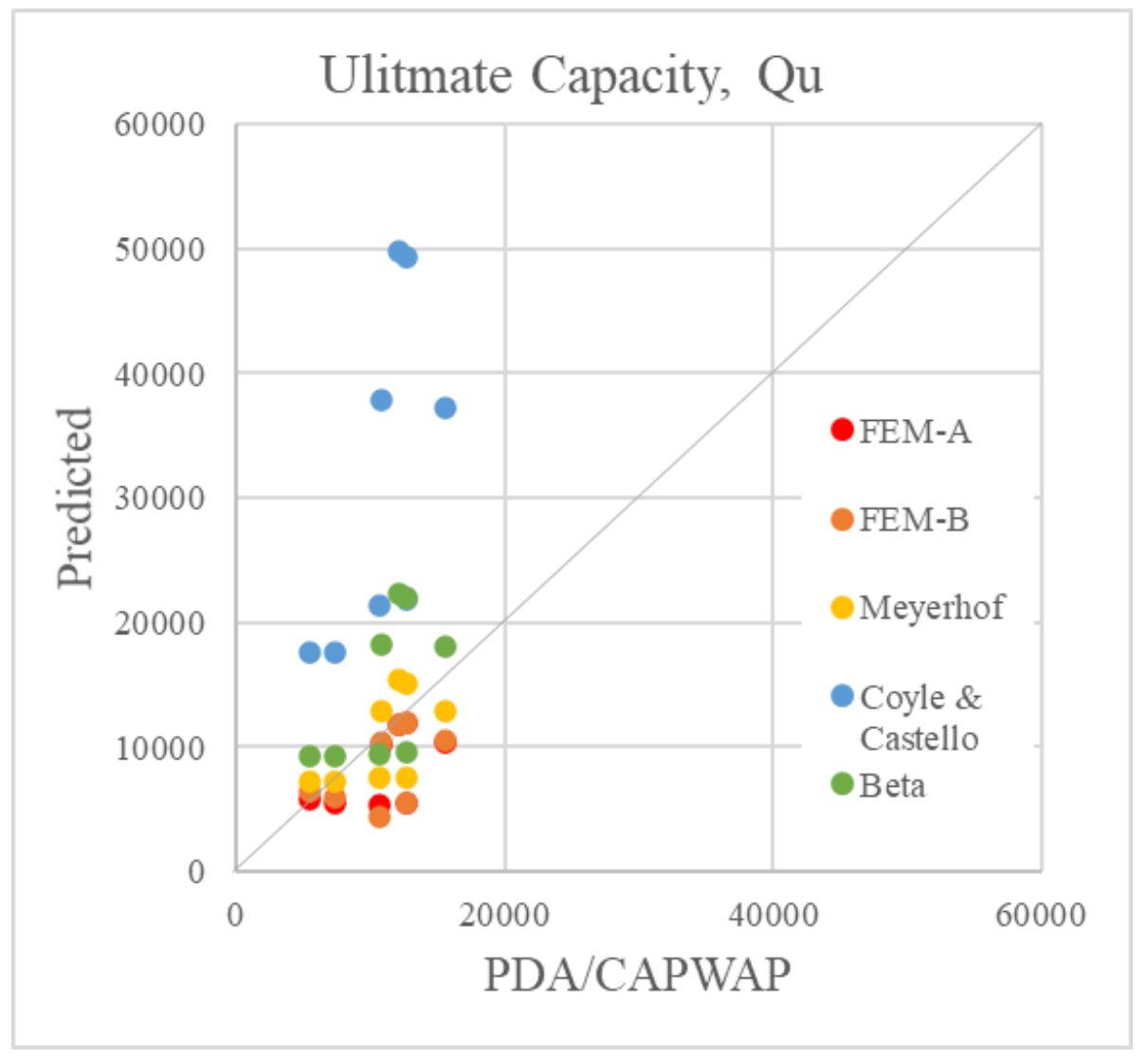

Figure 12. Qu: FEM and Analytical methods vs. in-situ (PDA) 


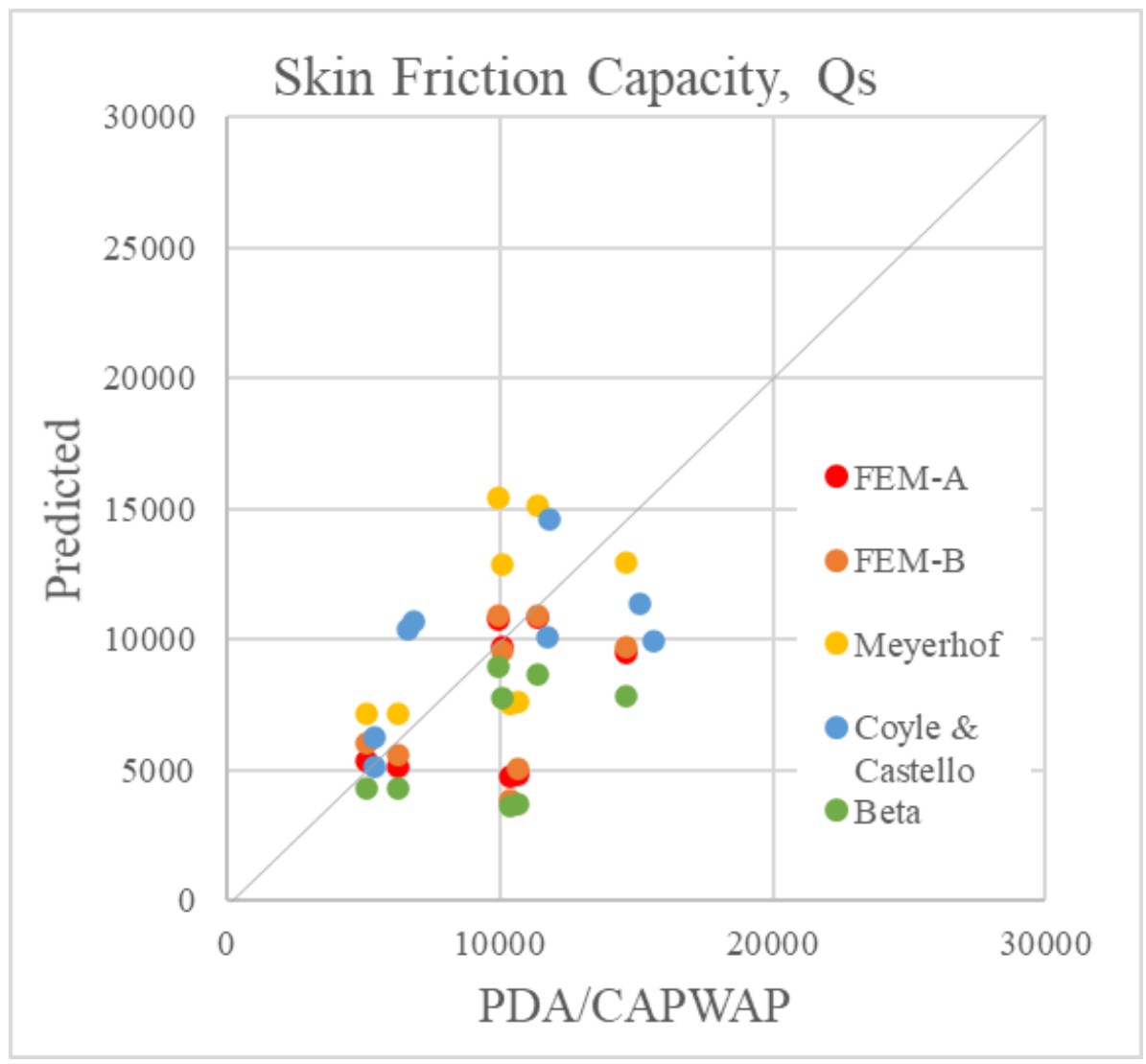

Figure 13. Qs: FEM and Analytical methods vs. in-situ (PDA)

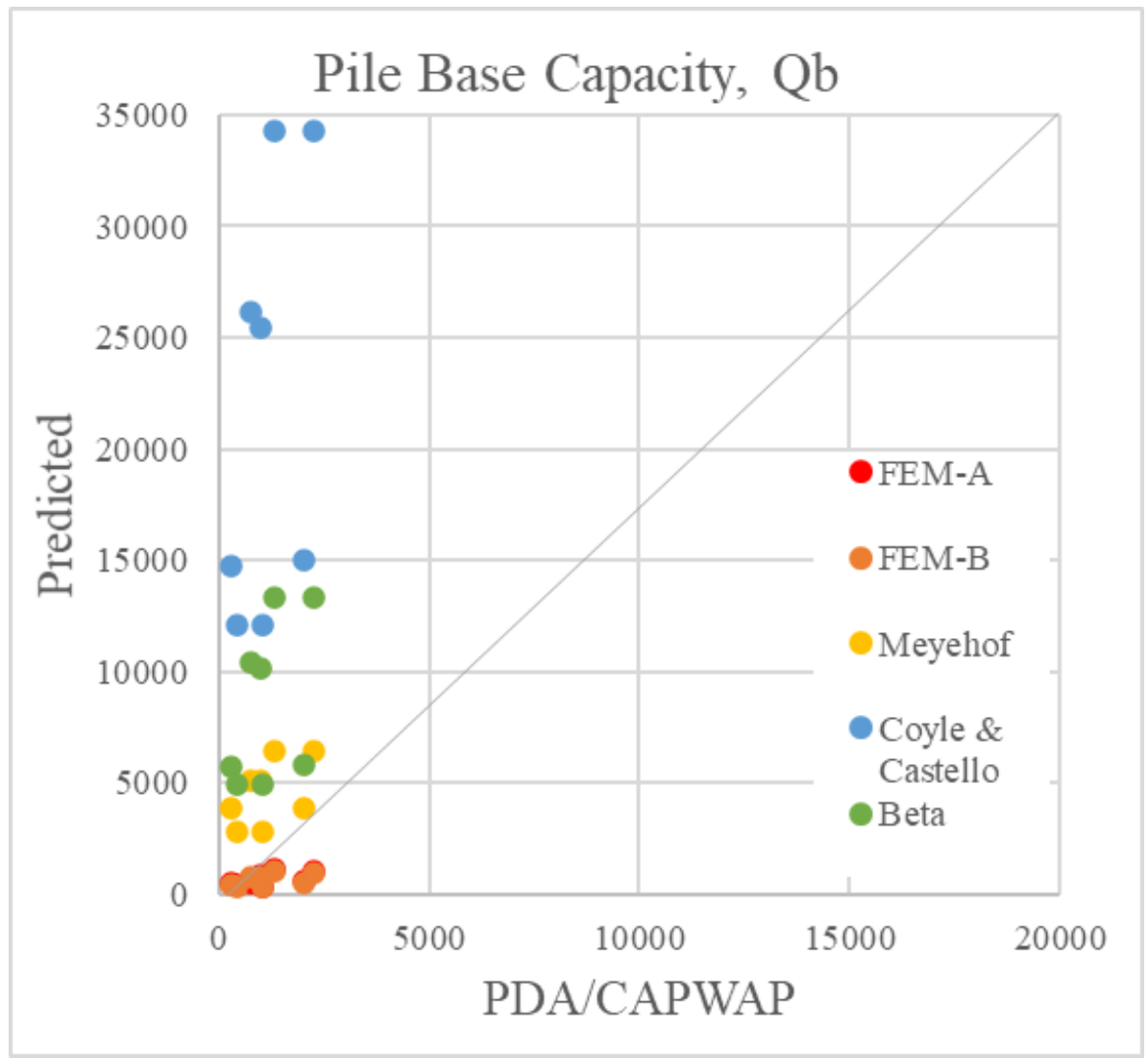

Figure 14. Qb: FEM and Analytical methods vs. in-situ (PDA) 
In addition, this observation resonates with the findings of Moryanto et al. [38]; the more elements in a FEM model, the more accurate the results.

Fig. 15 and 16 show the behavior of shear forces, along with the pile lateral surface, concerning the normal forces of pile models in FEM-A and FEM-B. It is observed that the models in relatively coarser mesh, FEM-B have more significant shear and normal forces than FEM-A models.

The graphs show that the pile-soil interaction, Mohr-Coulomb frictional model, is implemented successfully. Shear resistances have developed along the pile shaft. The ratio between the shear and normal forces in all models is equal to the implemented frictional coefficient of 0.45 .

Table 9. Regression Performance: FEM modeling and analytical methods vs. in-situ pile capacity

\begin{tabular}{|c|c|c|c|c|c|c|}
\hline \multicolumn{7}{|c|}{$\mathrm{Qu}$} \\
\hline Method & $\mathbf{R}$ & $\mathbf{F}$ & t-stat & P-value & SE & Ave. \%Err. \\
\hline FEM-A & 0.58 & 3.03 & 1.74 & 0.13 & 2685 & 23 \\
\hline FEM-B & 0.51 & 2.14 & 1.46 & 0.19 & 2880 & 25 \\
\hline Meyerhof & 0.61 & 3.60 & 1.90 & 0.11 & 3157 & 23 \\
\hline Coyle \& Castello & 0.62 & 3.80 & 1.96 & 0.10 & 11579 & 190 \\
\hline Beta & 0.59 & 3.15 & 1.78 & 0.13 & 5205 & 47 \\
\hline \multicolumn{7}{|c|}{ Qs } \\
\hline & $\mathbf{R}$ & $\mathbf{F}$ & t-stat & P-value & SE & Ave. \%Err. \\
\hline FEM-A & 0.52 & 2.22 & 1.49 & 0.19 & 2588 & 23 \\
\hline FEM-B & 0.44 & 1.47 & 1.21 & 0.27 & 2764 & 25 \\
\hline Meyerhof & 0.50 & 1.98 & 1.41 & 0.21 & 2206 & 35 \\
\hline Coyle \& Castello & 0.58 & 2.99 & 1.73 & 0.13 & 3757 & 27 \\
\hline Beta & 0.50 & 1.98 & 1.41 & 0.21 & 2206 & 35 \\
\hline \multicolumn{7}{|c|}{$\mathrm{Qb}$} \\
\hline & $\mathbf{R}$ & $\mathbf{F}$ & t-stat & P-value & SE & Ave. \%Err. \\
\hline FEM-A & 0.54 & 2.47 & 1.57 & 0.17 & 270 & 41 \\
\hline FEM-B & 0.43 & 1.39 & 1.18 & 0.28 & 259 & 38 \\
\hline Meyerhof & 0.50 & 1.97 & 1.40 & 0.21 & 1338 & 454 \\
\hline Coyle \& Castello & 0.47 & 1.66 & 1.29 & 0.25 & 9049 & 2395 \\
\hline Beta & 0.45 & 1.52 & 1.23 & 0.26 & 3509 & 890 \\
\hline
\end{tabular}

Table 10. Settlements at Ultimate Capacity

\begin{tabular}{|c|c|c|c|c|c|c|}
\hline \multirow{2}{*}{ Model } & \multirow{2}{*}{$\mathbf{D}(\mathbf{m})$} & \multirow{2}{*}{$\mathbf{L}(\mathbf{m})$} & \multicolumn{2}{|c|}{ FEM-A } & \multicolumn{3}{|c|}{ FEM-B } \\
\cline { 4 - 7 } & & & $\mathrm{s}(\mathrm{mm})$ & $(\mathrm{s} / \mathrm{D}) \%$ & $\mathrm{~s}(\mathrm{~mm})$ & 33 \\
\hline O-AB-A & 1.4 & 30 & 38 & 2.7 & 32 & 2.4 \\
\hline O-AB-B & 1.4 & 30 & 37 & 2.6 & 44 & 2.3 \\
\hline O-P-1 & 1.8 & 40 & 46 & 2.6 & 44 & 2.4 \\
\hline O-P-2 & 1.8 & 40 & 46 & 2.6 & 44 & 3.7 \\
\hline K-AB-A & 1.2 & 35 & 31 & 2.6 & 44 & 3.7 \\
\hline K-AB-B & 1.2 & 35 & 27 & 2.3 & 44 & 2.8 \\
\hline K-P-1 & 1.6 & 40 & 41 & 2.6 & 44 & 2.8 \\
\hline K-P-2 & 1.6 & 40 & 43 & 2.7 & 2.7 \\
\hline
\end{tabular}




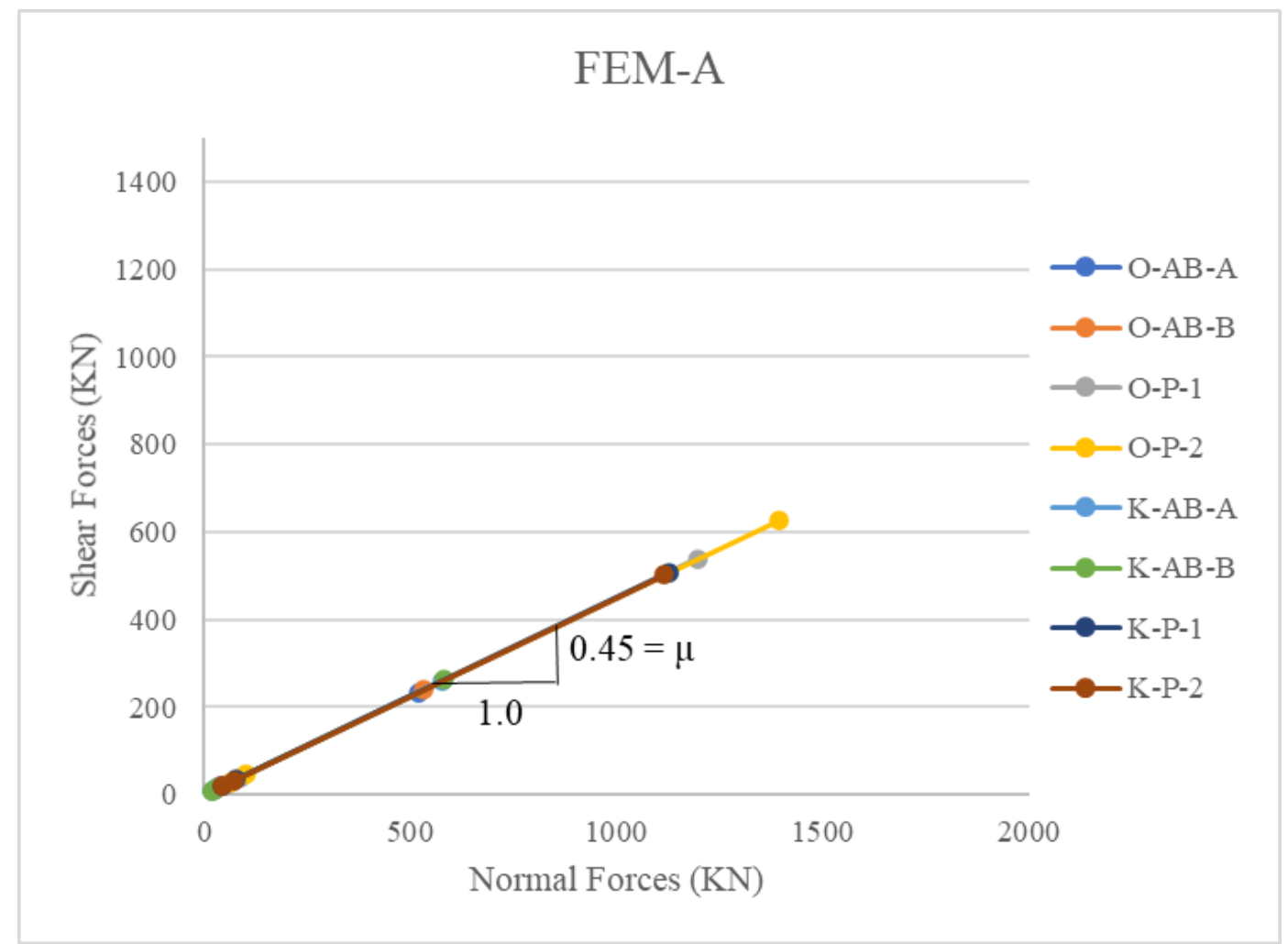

Figure 15. FEM-A: Shear forces vs. Normal forces along the Pile Lateral Surface

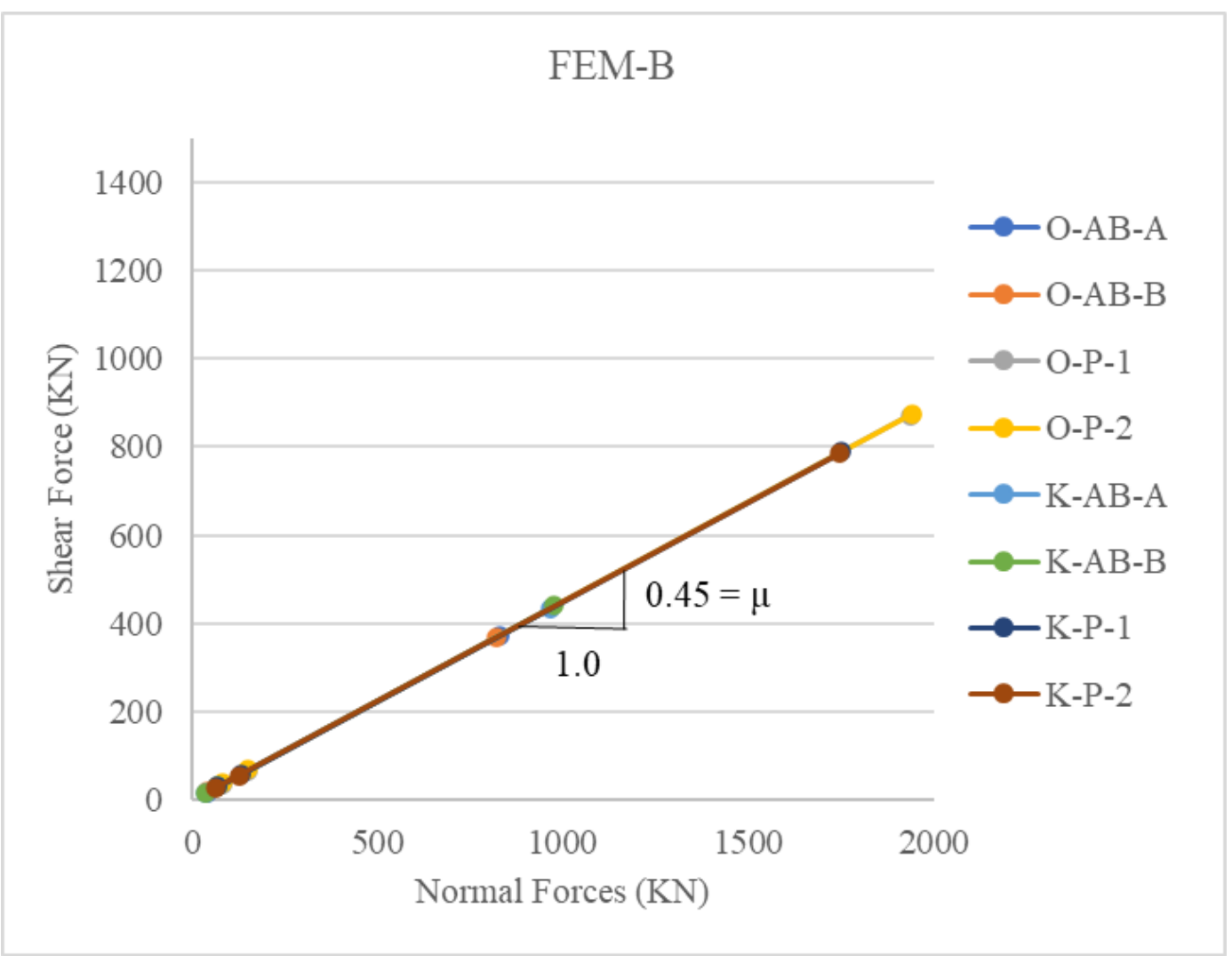

Figure 16. FEM-A: Shear forces vs. Normal forces along the Pile Lateral Surface 


\subsection{Settlements}

Table 10 shows the pile settlements (s) of FEM models at the ultimate capacity and their percentage relative to pile diameter (s/D \%). The relatively finer mesh model, FEM-A, has settlements that yielded $2.3 \%$ to $2.7 \%$ of their pile diameters. It is observed that settlements are more significant in larger diameters and longer piles. Pile models of Osmeña site O-P-1 and O-P-2 (D = $1.8 \mathrm{~m}$ and $\mathrm{L}=40 \mathrm{~m})$ have settled $46 \mathrm{~mm}$, and piles O-AB-A and O-AB-B $(\mathrm{D}=$ $1.4 \mathrm{~m}$ and $\mathrm{L}=30 \mathrm{~m}$ ) has reached settlements of 38 and 37 $\mathrm{mm}$, respectively. Similar to pile models of Kasilak site K-P-1 and K-P-2 $(\mathrm{D}=1.6 \mathrm{~m}$ and $\mathrm{L}=40 \mathrm{~m})$, settlements reached $41 \mathrm{~mm}$ and $43 \mathrm{~mm}$, respectively. Piles K-AB-A and $\mathrm{K}-\mathrm{AB}-\mathrm{B}(\mathrm{D}=1.2 \mathrm{~mm}$ and $\mathrm{L}=35 \mathrm{~mm})$ have settlements of $31 \mathrm{~mm}$ and $27 \mathrm{~mm}$, respectively.

The relatively coarser mesh model, FEM-B, has settlements that have yielded $2.3 \%$ to $2.8 \%$ of their pile diameters. Pile models of Osmeña site O-P-1 and O-P-2 have reached settlements of $44 \mathrm{~mm}$. Piles O-AB-A and O-AB-B reached settlements $33 \mathrm{~mm}$ and $32 \mathrm{~mm}$, respectively. While all of the pile models of the Kasilak site, K-AB-A, K-AB-B, K-P-1, K-P-2, have settled 44 mm.

\section{Conclusions}

A FEM modeling of eight bored piles is conducted in this study. Four-node axisymmetric elements (CAX4) are adopted in the soil and pile geometry. In representing the behavior of silty-sand soils, the modified Drucker-Prager Cap model is used. The cap hardening data was obtained using a plastic volumetric strain equation derived from a semi-log plot and implemented in the FEM models. This procedure is achieved by obtaining the $\mathrm{Cc}$ and $\mathrm{Cs}$ values using the proposed regression equations from the literature.

The utilized regression equations are applicable for all-natural soils, low plasticity soils, normally consolidated soils, and clayey soils. These equations are assumed to be applicable to the soils in the present study, the silty sand soils.

The pile-soil frictional interaction is modeled using Mohr-Coulomb friction behavior. The ultimate capacity of FEM models was determined through the generated load-settlement curves, and the double tangent method is applied to estimate the magnitude of the ultimate capacity. The point bearing resistance is determined by determining the axial force exerted on the soil from this ultimate capacity magnitude. The skin friction resistance is calculated by deducting the calculated point bearing capacity from the estimated ultimate capacity.

The ultimate capacity of the models was determined and validated using the PDA/CAPWAP results. The statistical performance was compared to the performance of the widely used analytical methods.
From the experimental procedures in this study, the FEM models created have conservative values for ultimate pile capacity compared to the in-situ values. Moreover, the set of FEM models that relatively finer mesh have a moderate positive correlation for the ultimate skin friction and pile base capacities against the PDA/CAPWAP results. The FEM capacity results have fewer statistical errors compared to the used analytical methods. The FEM models with more elements and finer mesh have better performance than coarser mesh models.

The correlation coefficient of the finer mesh models (FEM-A) has 0.58, 0.52, and 0.54 for Qu, Qs, and Qb, respectively. These models have average percentage errors of $23 \%(\mathrm{Qu}), 23 \%(\mathrm{Qs})$, and $41 \%(\mathrm{Qb})$ and standard errors of $2685 \mathrm{KN}(\mathrm{Qu}), 2588 \mathrm{KN}$ (Qs), and $270 \mathrm{KN}(\mathrm{Qb})$.

The settlements of the better-performing FEM models range from $2.3 \%$ to $2.7 \%$ against their respective pile diameters. It is observed that larger diameter and longer piles can have a more considerable amount of settlements before the ultimate capacity is achieved. Relatively large settlements reach up to 41 to $46 \mathrm{~mm}$, while the minor settlements are recorded, ranging from 27 to $37 \mathrm{~mm}$. Moreover, Meyerhof's method [35] has fewer standard errors and percentage errors among the analytical methods for cohesionless soils. Additionally, it has closer values of pile resistances to the FEM models' results.

\section{Limitations and Recommendations}

The data for the soil strata and pile-testing capacity through the HSDT is secondary data. These are taken from the Department of Public Works and Highways (DPWH), Region XI, Davao City, Philippines. Despite maximum efforts to gather all essential information, the researcher is unexempted to lack information and data. The implemented values for the soil-lateral coefficient and modulus of elasticity can be less accurate, which could also explain the conservative results from FEM models.

The FEM results have conservative values. However, it is observed that it produces consistently lower percentage errors compared to the utilized analytical methods. The methods in this study in implementing a single pile FEM model can be used to determine ultimate pile capacity for verification purposes.

The software used in this study is a student version of ABAQUS, which limits the number of nodes to one thousand. It is observed in this study that the models that have finer mesh sizes have better statistical performances compared to the coarse-meshed models. An implementation of finer mesh sizes could improve the statistical performance of the current study. However, it is not implemented in the present study. The utilized software is a student version due to the limited expense of the researcher. 
Ultimate Capacity Determination of Bored Piles Embedded in Silty-Sands Using Modified Drucker-Prager Cap Model

\section{REFERENCES}

[1] K. Teraghi, R.B. Peck and G. Mesri, Soil Mechanics in Engineering Practice, $3^{\text {rd }}$ ed., John Wiley and Sons, INC., 1996.

[2] M. Tomlinson and J. Woodward. Pile Design and Construction Practice, 5th ed., Taylor and Francis, 2008.

[3] G. S. Budi, M. Kosasi, D. H. Wijaya, Bearing Capacity of Pile Foundations Embedded in Clays and Sands Layer Predicted Using PDA Test and Static Load Test, Science Direct, Procedia Engineering, pp. 406-408, 2015.

[4] G. Likins, \& F. Rausche, Correlation of CAPWAP with Static Load Tests, Online available from Microsoft Word SW2004-SP08 - CW Correlation final.doc (pile.com)

[5] TA Pham, H-B Ly, VQ Tran, LV Giap, H-LT Vu, H-AT Duong, Prediction of Pile Axial Bearing Capacity Using Artificial Neural Network and Random Forest. Applied Sciences, Vol 10(5), 2020.

[6] H. Chen, Fundamentals of Finite Element Methods, 2016, Online available from: s272content.pdf (pdhonline.com)9

[7] G. B. Estores \& B. A. Lejano, Pull-Out Strength Of An Expansion Stud Anchor in Carbon Fiber Reinforced Concrete, International Journal of GEOMATE, Vol 12, Issue 31, pp. 1-8, 2017.

[8] S. Dandagawhal, Settlement Analysis of Pile Foundation Using Plaxis 2D, ResearchGate, International Journal of Science and Research, Vol. 8, No. 9, pp. 1706-1714, 2019.

[9] Majeed, \& O. Haider, Simulation of bearing capacity of bored piles, MATEC Web of Conferences, Vol. 162, pp. 1-7, 2018.

[10] S. Helwany, Applied Soil Mechanics with ABAQUS applications. John Wiley \& Sons, Inc. 2007.

[11] Y-G Zhan, H. Wang, F-C Liu, Modeling Vertical Bearing Capacity of Pile Foundation by Using ABAQUS. ResearchGate. Vol. 17, pp. 1855-1865, 2012.

[12] S. Gowthaman, M.C.M. Nasvi, and S. Krishnya, Numerical Study and Comparison of the Settlement Behaviours of Axially Loaded Piles using Different Material Models. Engineer: Journal of the Institution of Engineers, Sri Lanka, 50(2), pp. 1-10, 2017.

[13] J. H. Lee \& R. Salgado, Determination of Pile Base Resistance in Sands, Journal of Geotechnical and Geoenvironmental Engineering, Vol. 125, No. 8, August 1999.

[14] K. Józefiak, A. Zbiciak, M. Maslakowski, T. Piotrowski, Numerical modeling and bearing capacity analysis of pile foundation, ScienceDirect, Procedia Engineering (2015) $111,356-363$.

[15] Mosadegh \& H. Nikraz, Bearing Capacity Evaluation of Footing on a Layered - Soil using ABAQUS, Earth Science \& Climatic Change, Vol 6(3): 264, 2015.

[16] F. Pooya Nejad, M. B. Jaksa, M. Kakhi, B. A. McCabe,
Prediction of pile settlement using artificial neural networks based on standard penetration test data, ScienceDirect, Computers and Geotechnics, Vol 36(7), pp. 1125-1133, 2009.

[17] F. Pooya Nejad \& M. B. Jaksa, Load-settlement behavior modeling of single piles using artificial neural networks and CPT data, ScienceDirect, Computers and Geotechnics, Vol 89, pp. 9-21, 2017.

[18] Wrana, Pile Load Capacity - Calculation Methods, Studia Geotechnica et Mechanica, Vol. 37, No. 4, 2015.

[19] Toprak, O. Sevim, E. Topic and I. Kalkan, The Functions of Pile Types and Piles Used in Construction, International Journal of Advances in Mechanical and Civil Engineering, Vol 5, Issue 2, pp. 34-36, 2018.

[20] S. Sandler, Review of the development of Cap Models for geomaterials, IOS Press, Shock and Vibration, Vol 12, pp. 67-71, 2005.

[21] H. Shin \& J. Kim, Physical interpretations for cap parameters of the modified Drucker-Prager cap model in relation to the deviator stress curve of a particulate compact in conventional triaxial test, ELSEVIER, Power Technology, Vol 280, pp. 94-102, 2015.

[22] Ibrahim, A. Dif, \& W. Othman, Nonlinearity analysis in studying shallow grid foundation, ELSEVIER, Alexandria Engineering Journal, Vol 57, pp. 859-866, 2018.

[23] Z. R., Moayed, S. Tamassoki, \& E. Izadi, Numerical Modeling of Direct Shear Tests on Sandy Clay, Engineering and Technology International Journal of Civil and Environmental Engineering, Vol 6, No. 1, 2012.

[24] S. Desai \& H. J. Siriwardane, Constitutive Laws for Engineering Materials, Prenctice-Hall, Inc., 1984.

[25] S. Azzouz, R. J. Krizek, \& R. B. Corotis, Regression Analysis of Soil Compressibility, Soils and Foundations, Vol 16(2), pp. 19-29, 1976.

[26] M. Lav \& A. M. Ansal, Regression Analysis of Soil Compressibility, Turk $J$ Engin Environ Sci, Vol 25, pp. 101-109, 2001, Online available from: https://citeseerx.ist. psu.edu/viewdoc/download?doi=10.1.1.473.9102\&rep=rep $1 \&$ type $=$ pdf

[27] N. S. Isik, Estimation of swell index of fine grained soils using regression equations and artificial neural networks, Scientific Research and Essay, Vol 4(10), pp. 1047-1056, October 2009.

[28] R. M. Al-Kahdaar, A. F. I. Al-Ameri, Correlations between physical and mechanical properties of Al-Ammarah soil in Messan Governorate. Journal of Engineering, Vol 16(4), pp. 5946-5957, 2010.

[29] H. Park \& S.R. Lee, Evaluation of the compression index of soils using an artificial neural network. Computers and Geotechnics, Vol 38, pp. 472-481, 2011.

[30] Alptekin \& H. Taga, Prediction of Compression and Swelling Index Parameters of Quaternary Sediments from Index Tests at Mersin District, Open Geosciences, Vol 11, Issue 1, pp. 482-491, 2019.

[31] National Structural Code of the Philippines, Vol 1, $7^{\text {th }}$ ed., Association of Structural Engineers of the Philippines, Inc., 2016. 
[32] American Society for Testing and Materials, High-Strain Dynamic Testing of Deep Foundations, D4945-12, ASTM International, 2017.

[33] M. Das, Principles of Foundation Engineering, $8^{\text {th }}$ ed., CENGAGE Learning, 2016.

[34] Modified Drucker-Prager/Cap Model, 2017, Online available: https://abaqus-docs.mit.edu/2017/English/SIMA CAEMATRefMap/simamat-c-capplastic.htm\#simamat-c-c applastic-t-PlasticFlow-sma-topic6

[35] G. G. Meyerhof, Bearing Capacity and Settlement of Pile Foundations, Journal of Geotechnical Engineers, American Society of Civil Engineers, Vol 103, No. GT3, pp. 197-228, 1976.

[36] N. Janbu, Static bearing capacity of friction piles,
Proceedings of the $6^{\text {th }}$ European Conference on Soil Mechanics and Foundations Engineering, Vol. 1.2, 479488, 1976.

[37] C. Montgomery \& G. C. Runger, Applied Statistics and Probability for Engineers, $6^{\text {th }}$ ed., Wiley, 2014.

[38] Eko Tavip Maryanto, Rezza Ruzuqi, Victor Danny Waas, "Strength Analysis of Soil Retaining Wall Using Numerical Method of Manokwari Landfill," Civil Engineering and Architecture, Vol. 9, No. 3, pp. 682-689, 2021. DOI: 10.13189/cea.2021.090311.

[39] C. Drucker and W. Prager, SOIL MECHANICS AND PLASTIC ANALYSIS OR LIMIT DESIGN, Brown University, Quarterly of Applied Mathematics, Vol 10, No 2, 1952, Online available from: http://www.jstor.org/stable 143633942 